\title{
Synoptic Reorganization of Atmospheric Flow during the Last Glacial Maximum*
}

\author{
Flávio Justino+ \\ Leibniz Institut für Meereswissenschaften, IfM-GEOMAR, Kiel, Germany \\ AXEl TimmermanN \\ IPRC, SOEST, University of Hawaii at Manoa, Honolulu, Hawaii \\ Ute Merkel \\ Leibniz Institut für Meereswissenschaften, IfM-GEOMAR, Kiel, Germany \\ ENIO P. SOUZA \\ Universidade Federal de Campina Grande, DCA-UFCG, Bodocongó, Campo Grande, Brazil
}

(Manuscript received 28 April 2004, in final form 15 December 2004)

ABSTRACT

\begin{abstract}
A coupled global atmosphere-ocean model of intermediate complexity is used to study the influence of glacial boundary conditions on the atmospheric circulation during the Last Glacial Maximum in a systematical manner. A web of atmospheric interactions is disentangled, which involves changes in the meridional temperature gradient and an associated modulation of the atmospheric baroclinicity. This in turn drives anomalous transient eddy momentum fluxes that feed back onto the zonal mean circulation. Moreover, the modified transient activity (weakened in the North Pacific and strengthened in the North Atlantic) leads to a meridional reorganization of the atmospheric heat transport, thereby feeding back onto the meridional temperature structure. Furthermore, positive barotropic conversion and baroclinic production rates over the Laurentide ice sheets and the far eastern North Pacific have the tendency to decelerate the westerlies, thereby feeding back to the stationary wave changes triggered by orographic forcing.
\end{abstract}

\section{Introduction}

The climate of the Last Glacial Maximum (LGM; about $21000 \mathrm{yr}$ ago) is an interesting test case to study the importance of climate feedbacks. During the LGM, land characteristics were different from those observed at present, in the sense that, for example, parts of North America and northern Europe were covered by ice

\footnotetext{
* School of Ocean and Earth Science and Technology Publication Number 6573 and International Pacific Research Center Publication Number 320.

+ Current affiliation: Department of Atmospheric Physics, University of Toronto, Toronto, Ontario, Canada.
}

Corresponding author address: Dr. Flávio Justino, Department of Atmospheric Physics, University of Toronto, Toronto, ON M5S 1A7, Canada.

E-mail: fjustino@atmosp.physics.utoronto.ca caps. The atmospheric $\mathrm{CO}_{2}$ concentration was about $150 \mathrm{ppm}$ less than today and the global surface albedo differed from today's value due to the presence of ice caps and different vegetation patterns. Global climate simulations driven by LGM boundary conditions provide the possibility to understand why glacial climates were so different from today's climate.

Glacial climates have been subject of several complex modeling efforts focusing on ice sheet variations (e.g., DeBlonde and Peltier 1990; MacAyeal 1993; Marshall and Clarke 1999; Schmittner et al. 2002), as well as on the atmospheric (e.g., Rind 1987; Cook and Held 1988; Shinn and Barron 1989; Dong and Valdes 1998; Kitoh et al. 2001; Hewitt et al. 2001) and oceanic circulation changes (Ganopolski et al. 1998; Liu et al. 2002; Shin et al. 2003). Recently, coupled atmosphereocean general circulation models (AOGCMs; Shin et al. 2003; Hewitt et al. 2001; Bush and Philander 1998; Kim et al. 2003; Peltier and Solheim 2004) and intermediate coupled models (e.g., Bjornsson and Mysak 2001; Ganopolski et al. 1998) have been used to im- 
prove our understanding of coupled mechanisms of past climate change.

The goal of our study is to explore the influence of glacial boundary conditions on the atmospheric circulation in a systematical way using a global coupled atmosphere-ocean-sea ice model. We will focus in particular on the reorganization of the large-scale flow and its synoptic variability by diabatically induced eddy forcing. The study follows to some extent the analysis of Rind (1987), who analyzed the response of the atmospheric circulation to changes in surface albedo, glacial topography, and changes of the radiative forcing using a forced atmospheric general circulation model (GCM). Glacial changes of transient eddy activity have been investigated with atmospheric GCMs by several authors (e.g., Dong and Valdes 1998). However, forced atmospheric GCMs assume an infinite oceanic heat capacity. Ocean-atmosphere feedbacks that may be crucial for the reorganization of atmospheric flow in certain areas are neglected. This caveat has been partially relaxed in studies using slab mixed layer ocean models that assume a fixed deep-to-surface ocean heat flux. This allows at least for thermally induced atmosphereocean interactions. Recently it has been emphasized by coupled modeling studies (Bush and Philander 1998; Timmermann et al. 2004) that oceanic dynamical changes during the LGM seem to be an important element in determining large-scale atmospheric flow patterns. This approach will be pursued here. It should however be noted that at this stage, even climate GCM (CGCM) simulations for the LGM are perhaps as little constrained, as coupled atmosphere-slab mixed layer model simulations.

The transient eddies provide the most efficient source for meridional transport of heat, moisture, and momentum. Their existence depends largely on the existing vertical wind shear and thus on the presence of meridional temperature gradients that maintain baroclinic conditions. Shortly after their generation, transient eddies also experience the strong horizontal shear in the region of the mean westerlies, leading to barotropic conversions and subsequent frictional decay. The most active regions for transient eddy production and propagation are called storm tracks. They can be deduced diagnostically from the time-averaged kinetic energy of the high-pass-filtered (e.g., 2-6 days) wind fluctuations. Changes of the meridional temperature gradients, as imposed by glacial boundary conditions are expected to modified the regional wind shear and the static stability of the air. Changes of the storm-track characteristics during the last glacial period may have an impact on heat, momentum, and freshwater transport with implications for the zonal mean atmospheric circulation, the oceanic circulation, and the growth and decline of the Laurentide and Scandinavian ice sheets (Bromwich et al. 1993). We focus here on the reorganization of large-scale flow due to changes in transient eddy activity. Different aspects of the reorganization will be traced back to the effect of individual boundary condition changes during the LGM. Along the same lines Cook and Held (1988) and Rind (1987) have tried to attribute the most important glacial changes of the atmospheric flow to either glacial topographic, albedo, or radiative forcing anomalies due to an overall $\mathrm{CO}_{2}$ reduction. These studies revealed that the glacial wintertime circulation in the Northern Hemisphere is most strongly influenced by topographic forcing, a conclusion that is supported by our study. The Laurentide ice sheet generates an upstream-blocking situation whereas the downstream low interacts with the upstream high generated by the European ice sheet. Stationary wave patterns in summer appear to be very sensitive to diabatic forcing due to albedo changes in the Northern Hemisphere. Storm-track changes go along with changes in precipitation with severe consequences also for the ice sheet mass balance. Hall et al. (1996) found that glacial storm-track changes will enhance snow accumulation over the Laurentide and Scandinavian ice sheets, thereby stabilizing the LGM. A more thorough assessment on this issue will be presented in the last section of this paper.

Our paper is organized as follows: After a description of the coupled atmosphere-ocean model Earth System Models of Intermediate Complexity (EMIC) Climate deBilt-Coupled Large-Scale Ice Ocean (ECBILTCLIO) we describe the setup of the LGM sensitivity experiments (section 2). In section 3, we discuss the mean circulation and storm-track changes due to different boundary conditions. In section 4, large-scale climate impacts of glacial storm-track changes are analyzed. Our paper concludes with a discussion and a summary of our main results.

\section{Model and experimental design}

The atmospheric component ECBILT (Opsteegh et al. 1998) of our coupled model is a three-layer model with a quasi-geostrophic adiabatic core (Marshall and Molteni 1993) and a set of physical parameterizations for the hydrological cycle (Held and Suarez 1978; Opsteegh et al. 1998) and a simplified radiation code. It runs in T21 triangular truncation, which corresponds to an approximate resolution of $5.6^{\circ}$ in both latitude and longitude. The coupled ocean-sea ice model CLIO (Goosse et al. 1999; Goosse and Fichefet 1999; Goosse et al. 2002) is based on the primitive equations using a free surface and thermodynamic/dynamic assumptions, 


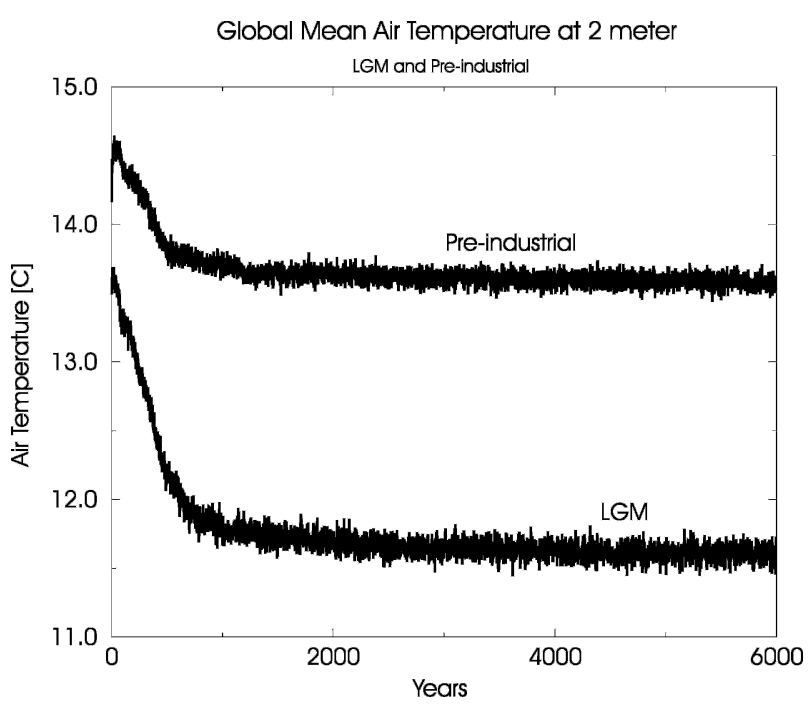

FIG. 1. Global mean annual surface temperature for the preindustrial control and the LGM simulation.

respectively. A parameterization of vertical mixing (Goosse et al. 1999) is used that represents a simplification of the Mellor and Yamada (1982) 2.5-level turbulence closure scheme. Furthermore, the ocean model
CLIO includes mixing along isopycnals and it captures the effect of mesoscale eddies on the transport (Gent and McWilliams 1990) as well as the dense water flow down topographic features (Campin and Goosse 1999). The horizontal resolution of CLIO is $3^{\circ}$ and there are 20 unevenly spaced vertical levels in the ocean. The individual models are coupled by exchanging momentum, freshwater, and heat. The simulations are performed with weak freshwater flux corrections. The model is computationally very efficient. On a DECalpha workstation a 200-yr-long simulation can be done within 1 day.

To investigate the differences between the LGM and preindustrial climate in a systematical way, we perform a series of sensitivity experiments. A 10 000-yr-long preindustrial control simulation (CTR) is performed. It employs an atmospheric $\mathrm{CO}_{2}$ concentration of $280 \mathrm{ppm}$ and present-day albedo, vegetation, orbital forcing, and topographic boundary conditions. As can be seen from Fig. 1 the simulated global mean temperature equilibrates after about $1000 \mathrm{yr}$ at a level of about $13.7^{\circ} \mathrm{C}$.

Figure 2 shows a comparison between the simulated annual mean temperature field at $2 \mathrm{~m}(\mathrm{t} 2 \mathrm{~m})$ and the "observed" temperature pattern obtained from the $\mathrm{Na}$ - (a) Air temperature $[\mathrm{C}]$

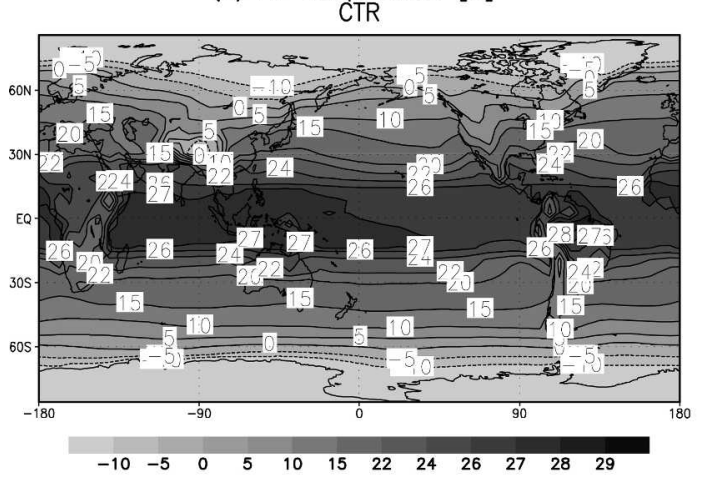

(b) Air temperature $[\mathrm{C}]$

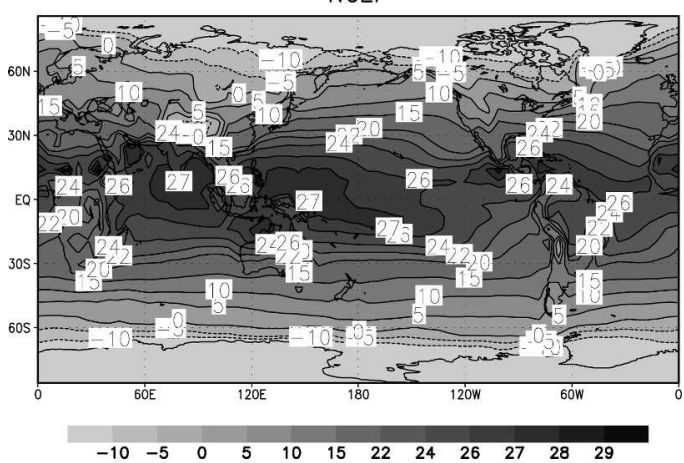

(c) Total precipitation $[\mathrm{m} / \mathrm{yr}]$

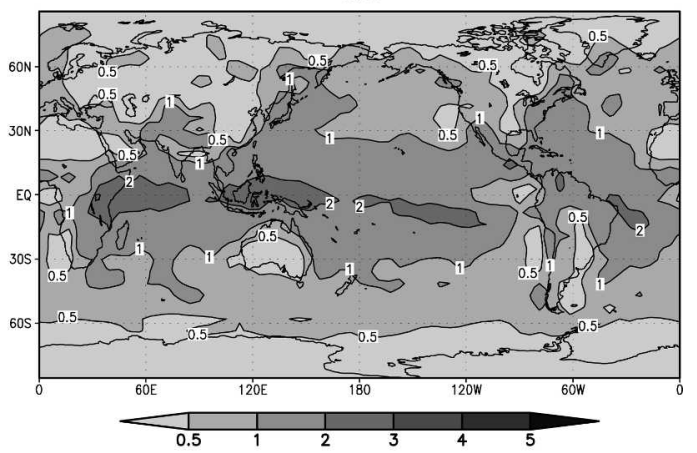

(d) Total precipitation $[\mathrm{m} / \mathrm{yr}]$
Xie and Arkin $(1997)$

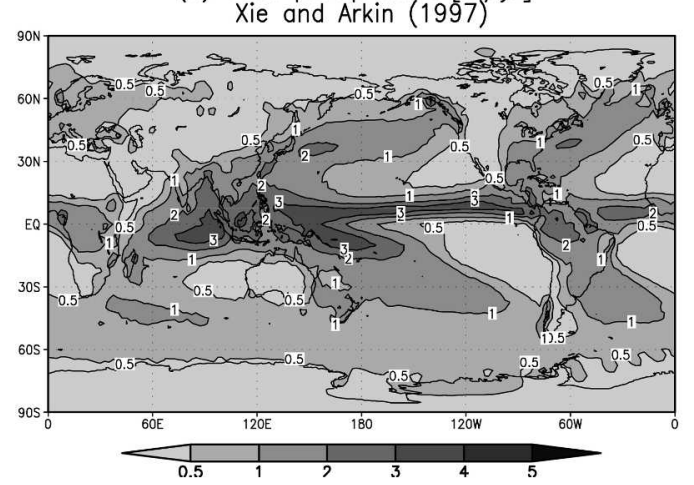

FIG. 2. Simulated mean surface air temperature distribution $\left({ }^{\circ} \mathrm{C}\right)$ for (a) the preindustrial control run and (b) the mean surface air temperature distribution obtained from the NCEP-NCAR reanalysis. (c) Same as (a), but for the total precipitation $\left(\mathrm{m} \mathrm{yr}^{-1}\right)$. (d) Total precipitation from Xie-Arkin dataset (Xie and Arkin 1997). 
tional Centers for Environmental Prediction-National Center for Atmospheric Research (NCEP-NCAR) reanalysis (Kalnay 1996) for the period 1980-2002. The simulated global mean annual 2-m temperature $\left(13.7^{\circ} \mathrm{C}\right)$ differs from the NCEP-NCAR data $\left(13.9^{\circ} \mathrm{C}\right)$ by $0.2^{\circ} \mathrm{C}$. Note also that the NCEP-NCAR reanalysis represents present-day climate, rather than preindustrial conditions. However, considerable local differences between model simulation and observations can be found in the Pacific cold tongue area, Antarctica, and over topographical features, such as the Tibetan Plateau and Greenland. The relative weakness of the trade winds leads to a zonally symmetric temperature structure in the tropical oceans. Simulated warm pool temperatures in the Pacific are hence underestimated and cold tongue temperatures are somewhat warmer than observed. The underestimation of 2-m air temperatures in mountainous areas is most pronounced in seasons of partial snow coverage (not shown). The largest differences between the model and observations however occur north of $65^{\circ} \mathrm{N}$. This deficiency can be partly attributed to an overestimation of the sea ice thickness and systematic errors in the simulated wind field over the Arctic Ocean.

The simulated precipitation field captures the most significant features of the Xie and Arkin data (Xie and Arkin 1997) qualitatively (Figs. 2c,d). In general, the simulated precipitation in the intertropical convergence zone (ITCZ) and the storm-track regions is underestimated as compared to the observations. Dryer conditions are simulated over the rain forest in Brazil and in central Africa where the simulated precipitation is about $35 \%$ lower than in the observations. On a zonally averaged basis (not shown) some of the regional differences between model and observations cancel each other out and the model results are more similar to the Climate Prediction Center's Merged Analysis of Precipitation (CMAP; Xie and Arkin 1997). Given the simplicity of our model the overall performance is satisfactory. A more detailed analysis of the performance of ECBILT and its dynamical response to climate perturbations can be found in previous studies (e.g., Opsteegh et al. 1998; Goosse et al. 1999, 2002; Timmermann et al. 2004).

To improve our understanding of the climate during the LGM, we systematically examine the consequences of different types of boundary changes on the atmospheric circulation. Five different experiments are performed. In the first sensitivity experiment (ALB) the surface albedo of the LGM ice sheets is prescribed. The albedo of the LGM is derived from a vegetation reconstruction (Crowley 1995) where the deforested soils and plant cover are replaced by their respective albedo. The inclusion of the ice sheets increases the albedo by more than $60 \%$ in North America and Europe. When averaged globally the land albedo in the LGM simulation is $7 \%$ higher than in the CTR case (hereafter ALB simulation). The second simulation uses an atmospheric $\mathrm{CO}_{2}$ concentration of $200 \mathrm{ppm}\left(\mathrm{CO}_{2}\right.$ simulation $)$. In the third simulation (TOPO), the anomalous orography of the LGM ice sheet is prescribed using the ICE-4G reconstruction of Peltier (1994). The orbital configuration of the LGM (Berger 1978) is taken into account in the fourth simulation (ORB). The experiments consist of a 1000-yr-long simulation, starting from equilibrated CTR conditions. Our analysis focuses on the last $300 \mathrm{yr}$, when each simulation has reached a new quasiequilibrium for the variables under consideration. The fifth 6000-yr-long simulation (LGM) takes into account the most relevant boundary changes of the LGM: changes in topography, $\mathrm{CO}_{2}$ concentration, ice sheet albedo, and orbital forcing. It is important to note that both topography and albedo files were interpolated to T21 resolution using bilinear interpolation. The ice sheet topography in the TOPO and LGM experiments is included as an anomaly between the ICE-4G reconstruction and present-day topography. This anomaly field is added to the default topography pattern of the atmospheric model ECBILT.

Based on previous experience with coupled LGM simulations, we disregard the role of sea level changes and ice sheet ablation (Marshall and Clarke 1999) in our simulations, although the latter may be very important for the temperature changes in the North Atlantic region as well as for the simulated sea ice cover.

As can be seen from Fig. 1, the global mean surface air temperature during the LGM equilibrates at a level of $11.5^{\circ} \mathrm{C}$, about $2.1^{\circ} \mathrm{C}$ lower than for the preindustrial control simulation. In comparison to the LGM simulation of Kim et al. (2003), the ECBILT-CLIO model exhibits a very low climate sensitivity, which may be attributed partly to the prescribed present-day cloud cover.

Figure 3 reveals that the strongest cooling occurs in the North American-North Atlantic region as well as in the extratropical Southern Hemisphere (not shown). A very pronounced warming can be found in the North Pacific area as well as over eastern Siberia. This feature is associated with a topographically induced blocking situation upstream of the Laurentide ice sheet, as will be shown below. The ALB experiment generates a strong local cooling over the ice cap areas, due to the enhanced reflection of shortwave radiation. The overall cooling of the Tropics is accompanied by reduced precipitation over the tropical oceans. The simulated La 

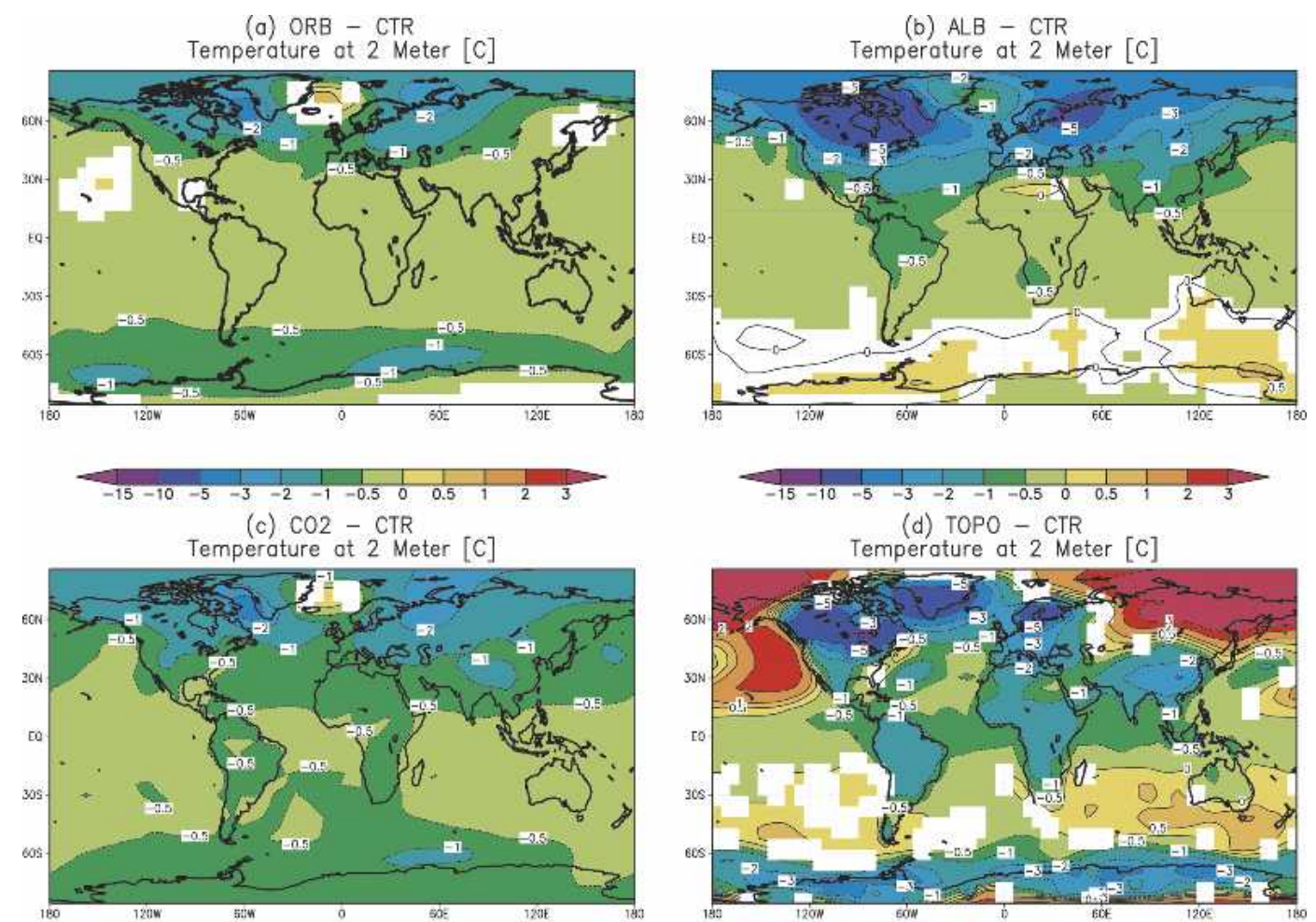

(d) TOPO - CTR

Temperature at 2 Meter [C]
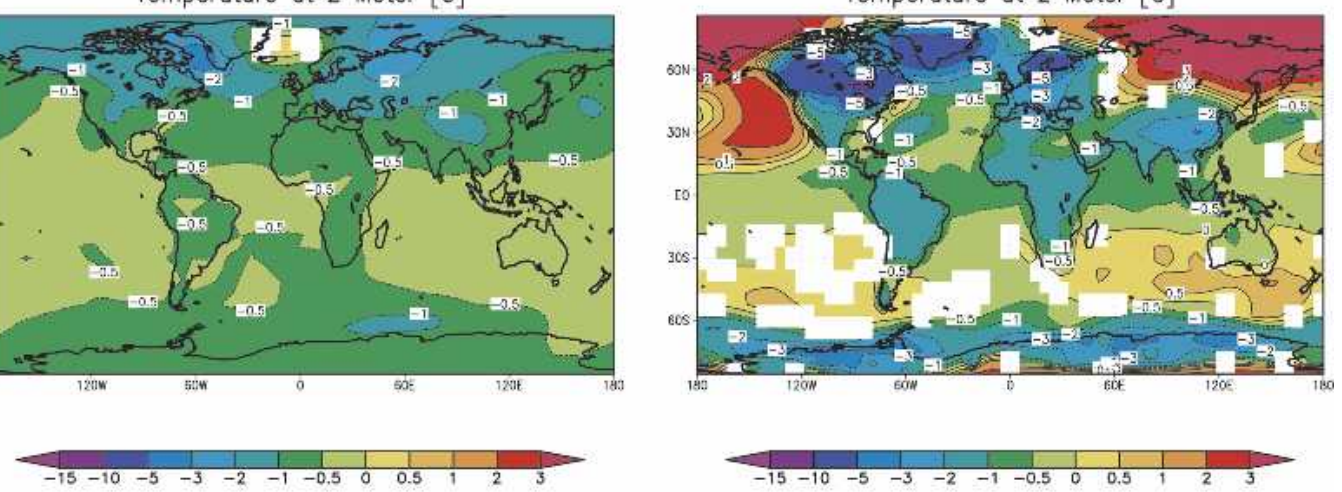

(e) LGM - CTR

Temperature at 2 Meter [C]
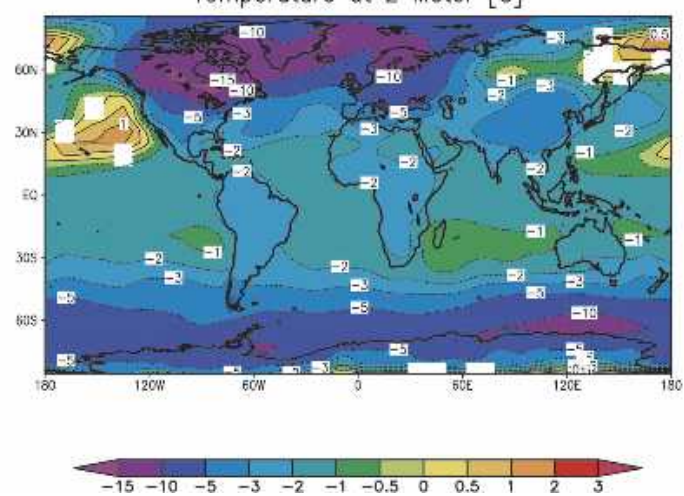

FIG. 3. Annual mean surface temperature anomalies $\left({ }^{\circ} \mathrm{C}\right.$ ) between (a) ORB-CTR, (b) ALB-CTR, (c) $\mathrm{CO}_{2}-$ CTR, (d) TOPO-CTR, and (e) LGM-CTR simulations. Shaded areas are statistically significant at the $95 \%$ level based on calculations of Student's $t$ test with 300 degrees of freedom.

Niña-type surface temperature and rainfall anomalies are consistent with some recent sea surface temperature (SST) reconstructions (see Timmermann et al. 2004 for a discussion) and lake level reconstructions of Kohfeld and Harrison (2000), as shown in Fig. 4.

Figure 5 shows the simulated SST for the control run as well as the differences between the five sensitivity runs and the control run. Albedo forcing generates a cooling of about $3^{\circ}$ in the North Atlantic region, down- stream of the Laurentide ice sheet. The reduction of the $\mathrm{CO}_{2}$ concentration and changes in the orbital parameters have their strongest response near the sea ice margins, indicating that sea ice albedo feedbacks can amplify local forcing due to changes in the boundary conditions (also documented by Fig. 3). The most prominent changes can be found for the TOPO simulation with a cooling by $1^{\circ}-2^{\circ} \mathrm{C}$ in the tropical oceans. All temperature changes discussed in this paper are 


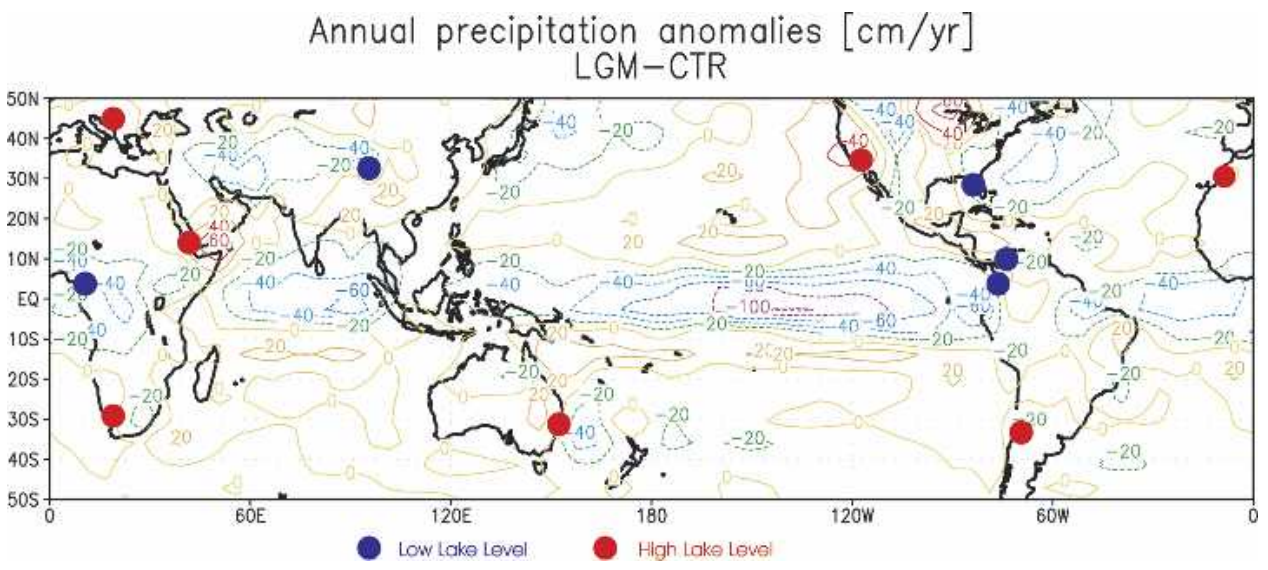

FIG. 4. Precipitation anomalies $\left(\mathrm{cm} \mathrm{yr}^{-1}\right)$ between the LGM and CTR simulations and reconstructed areas of enhanced and reduced precipitation from the lake level data of Kohfeld and Harrison (2000). Low/high lake level mean excess/deficit of precipitation compared to today, respectively.

statistically significant with respect to the $95 \%$ confidence band of a $t$ test.

Only small temperature anomalies are simulated in the subtropical oceans, whereas the northeastern Pacific exhibits a significant warming, which is described and explained in Timmermann et al. (2004). The combination of these effects (LGM simulation) illustrates that the North Pacific warming is weakened by the cooling tendencies of the other boundary changes. Furthermore, the extratropical oceans cool by up to $6^{\circ} \mathrm{C}$ and an overall equatorward extension of the sea ice margin can be found (see Fig. 6). The simulated sea ice extension in the LGM experiment compares well with the latest Glacial Atlantic Ocean Mapping (GLAMAP) reconstruction (Sarnthein et al. 2003; Pflaumann et al. 2003), as shown in Fig. 6.

A more thorough assessment of the SST changes during the LGM as well as an explanation of the mechanisms can be found in Timmermann et al. (2004). Figure 7 gives a comparison between the latest SST reconstruction (Pflaumann et al. 2003) and our simulated SST anomaly field. Note that GLAMAP uses Climate: Long-Range Investigation, Mapping, and Prediction (CLIMAP) SSTs (CLIMAP 1981) in the Pacific and Indian Oceans. Our simulation exhibits weaker anomalies in the North Atlantic than reconstructed, which can be partly attributed to the low climate sensitivity of our coupled model. Furthermore, the difference between observations and model simulation may be due to the fact that our simulation neglects background ablation from the ice sheets (Marshall and Clarke 1999), which may have an influence on the strength of the thermohaline circulation, and hence on SST. In general, however, there are many common features between the simulation and the global SST anomaly reconstruction. In the subtropical areas of the Southern Hemisphere
(SH), cooling is weakest. A belt of cold waters surrounds the Antarctic continent. A cooling of the Kuroshio can be found as well as a warming of the eastern North Pacific.

As depicted in Fig. 3f, the total (LGM-CTR) SST response is larger than the sum of the response to individual forcing agents. Previous LGM modeling studies (e.g., Broccoli and Manabe 1987; Rind 1987) have found strong $\mathrm{SH}$ oceanic cooling as a result of the reduced atmospheric $\mathrm{CO}_{2}$ concentration. The $\mathrm{CO}_{2}$ induced cooling in our $\mathrm{CO}_{2}$ run is very weak. The nonlinearity of our response suggests a very strong sea ice albedo feedback. Furthermore, the LGM simulation exhibits a stronger meridional overturning in the North Atlantic than the CTR run. This in turn can further cool the Southern Ocean, due to the seesaw effect (Stocker 1998). A more in-depth analysis of the Southern Hemispheric cooling is beyond the scope of this paper.

The comparison with lake level data, the GLAMAP sea ice reconstruction, and the GLAMAP SST reconstruction for the LGM reveal that the model of intermediate complexity used in this study is suitable for simulating basic features of the LGM climate quite realistically. In the following sections, we will study the role of atmospheric dynamics and air-sea interactions in setting up the LGM climate anomaly patterns.

\section{Changes of the storm tracks and the atmospheric mean circulation}

The atmospheric circulation during the LGM has been studied extensively using both atmospheric GCMs (Rind 1987; Cook and Held 1988; Hall et al. 1994, 1996; Dong and Valdes 1998, 2000) as well as coupled general circulation models (e.g., Bush and Philander 1998; Shin et al. 2003). So far, however, the role of the different 
(a) CTR
SST
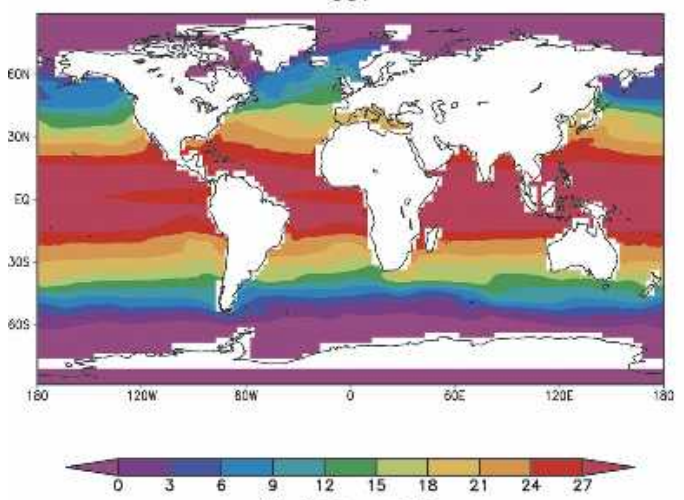

(c) $\mathrm{CO} 2$ - CTR

annual SST anomalies [C]
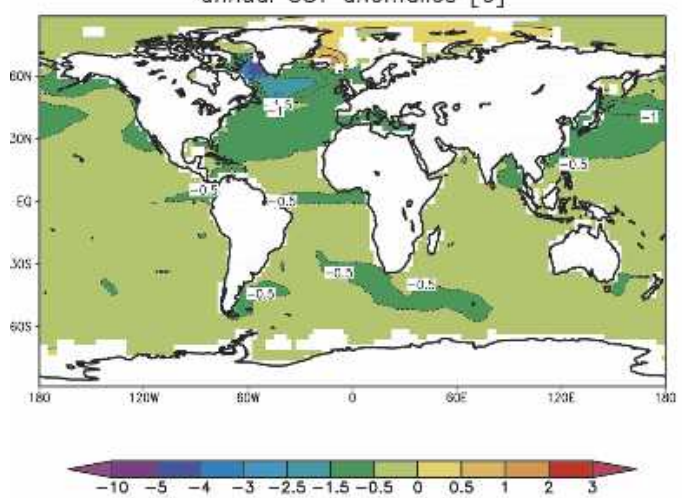

(e) TOPO - CTR

annual SST anomalies [C]

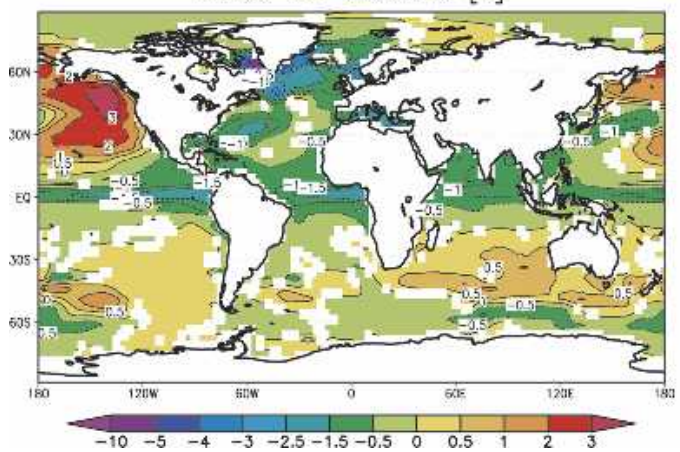

(b) ALB - CTR
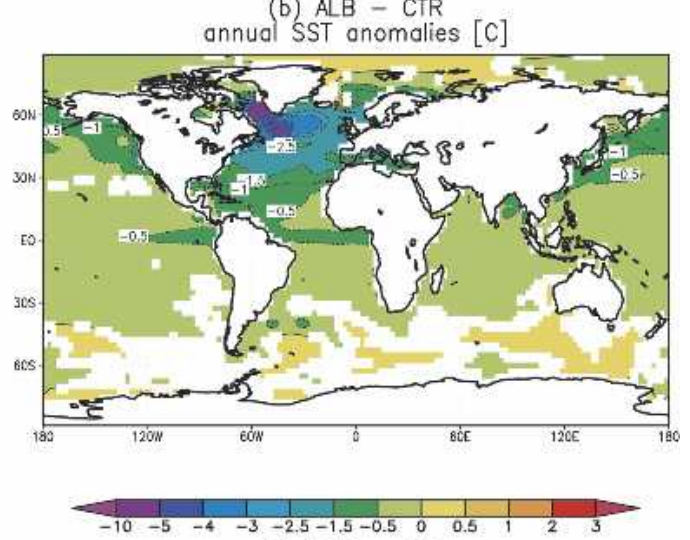

(d) ORB - CTR annual SST anomalies [C]
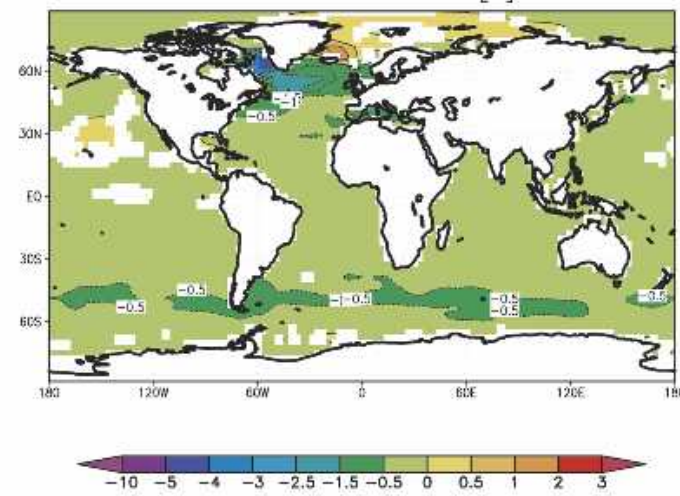

(f) $L G M$ - CTR

annual SST anomalies [C]

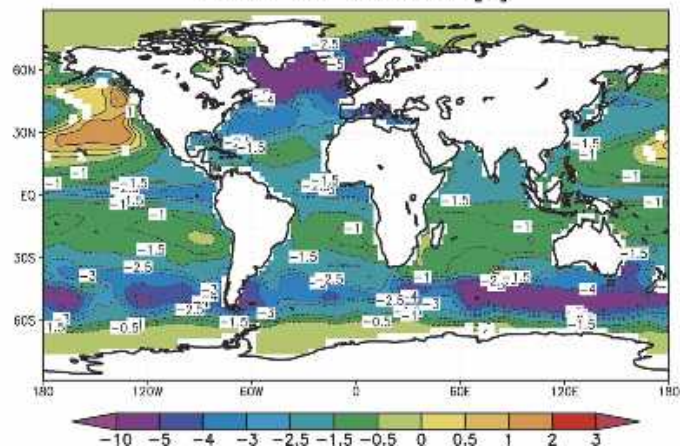

FIG. 5. (a) SST $\left({ }^{\circ} \mathrm{C}\right)$ for the CTR simulation, SST difference between (b) ALB-CTR, (c) $\mathrm{CO}_{2}-\mathrm{CTR}$, (d) ORB-CTR, (e) TOPO-CTR, and (f) LGM-CTR. Shaded areas are statistically significant at $95 \%$ level based on calculations of Student's $t$ test with 300 degrees of freedom.

boundary conditions in changing the atmospheric flow has not been explored systematically using global coupled atmosphere-ocean sea ice models. We focus on changes in atmospheric baroclinicity, as well as on the associated changes in the storm-track position and strength during the LGM. Changes of the transient eddy activity are accompanied by large-scale reorganizations of the poleward heat transport and feedback onto the atmospheric mean flow. Figure 8 serves as a "road map," guiding through the physical mechanisms that will be discussed in the following sections. The labeled numbers of the feedbacks will be used in the following subsections to identify which of the physical processes is discussed.

\section{a. Feedback 1: Thermal wind changes}

As shown in Fig. 3 strong changes of the meridional temperature gradient in the North Atlantic are generated by albedo, $\mathrm{CO}_{2}$, and topographic forcing during the LGM. In these cases, the northern North Atlantic 
(a) Sea ice margin - February ECBilt(solid), GLAMAP(dot dash), CLIMAP(dots)
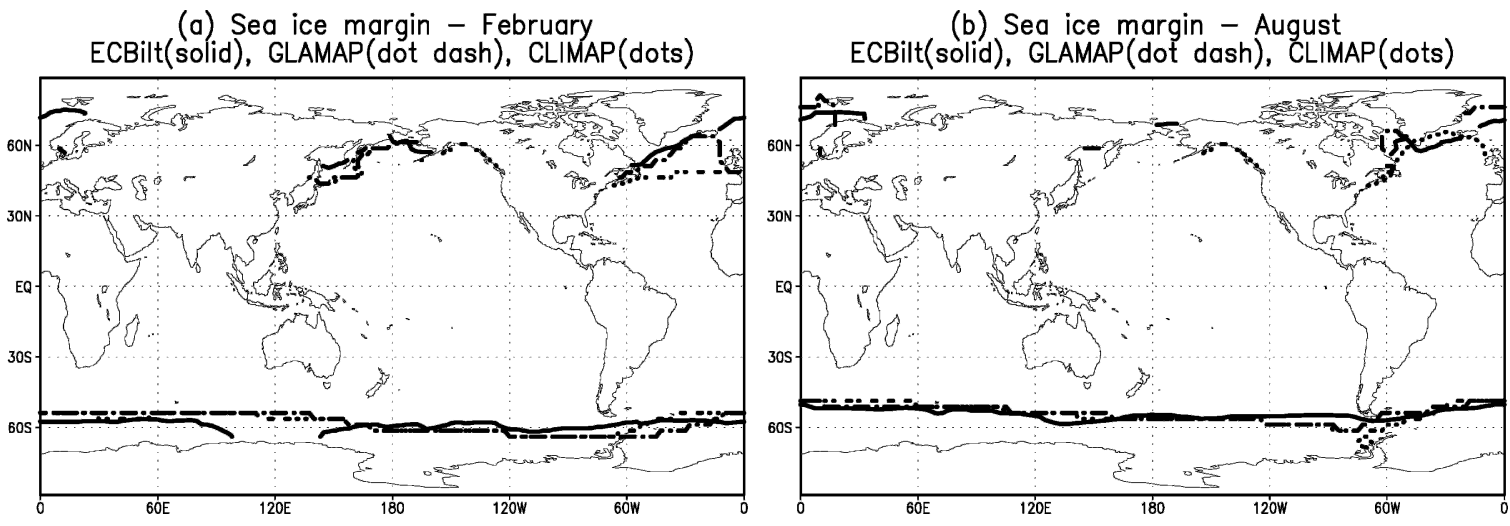

(b) Sea ice margin - August

FIG. 6. Sea ice margin in the LGM experiment and reconstructed from CLIMAP and GLAMAP for (a) Feb and (b) Aug.

cools down by several degrees, as compared to the preindustrial control simulation. This will enhance the vertical wind shear in the atmosphere, due to the thermal wind balance. In the North Pacific, however, a largescale warming leads to a weakening of the meridional temperature gradient and hence of the vertical shear. Furthermore, the large topographic anomalies induce stationary waves in the atmosphere, which change the mean circulation over the North Atlantic and North Pacific regions (see Fig. 9). Over the North Pacific and Arctic region an upstream equivalent barotropic high is generated due to the presence of the Laurentide ice sheet, whereas over the North Atlantic region a superposition takes place between the downstream Laurentide low and an upstream high triggered by the Scandinavian ice sheet with an overall baroclinic structure. Furthermore, these topographically forced wind anomalies have an influence on the simulated SST. Over the North Pacific an upstream-blocking situation leads to a reduced evaporative cooling of the North Pacific, and hence to warming (Timmermann et al. 2004). These factors lead to local reorganizations of the time-mean winds. The net effect of diabatically and topographically forced circulation changes on the zonal mean circulation is depicted in Fig. 10. Due to the different forcing conditions in the North Pacific and North Atlantic, a delicate balance is established between zonal flow weakening and amplification, respectively. On a zonal mean basis, however, the Pacific outweighs the North Atlantic atmospheric circulation changes, as can be seen from Fig. 10. The zonally averaged circulation exhibits a weakening of the Northern Hemispheric jet stream, in particular at its southern flank, with implications for the global stationary and transient eddy momentum transport as well as for the meridional vertical circulation (Kuo 1956). The weakening of the Northern and Southern Hemispheric zonal mean jet streams by about $10 \%$ can be traced back to the domi-
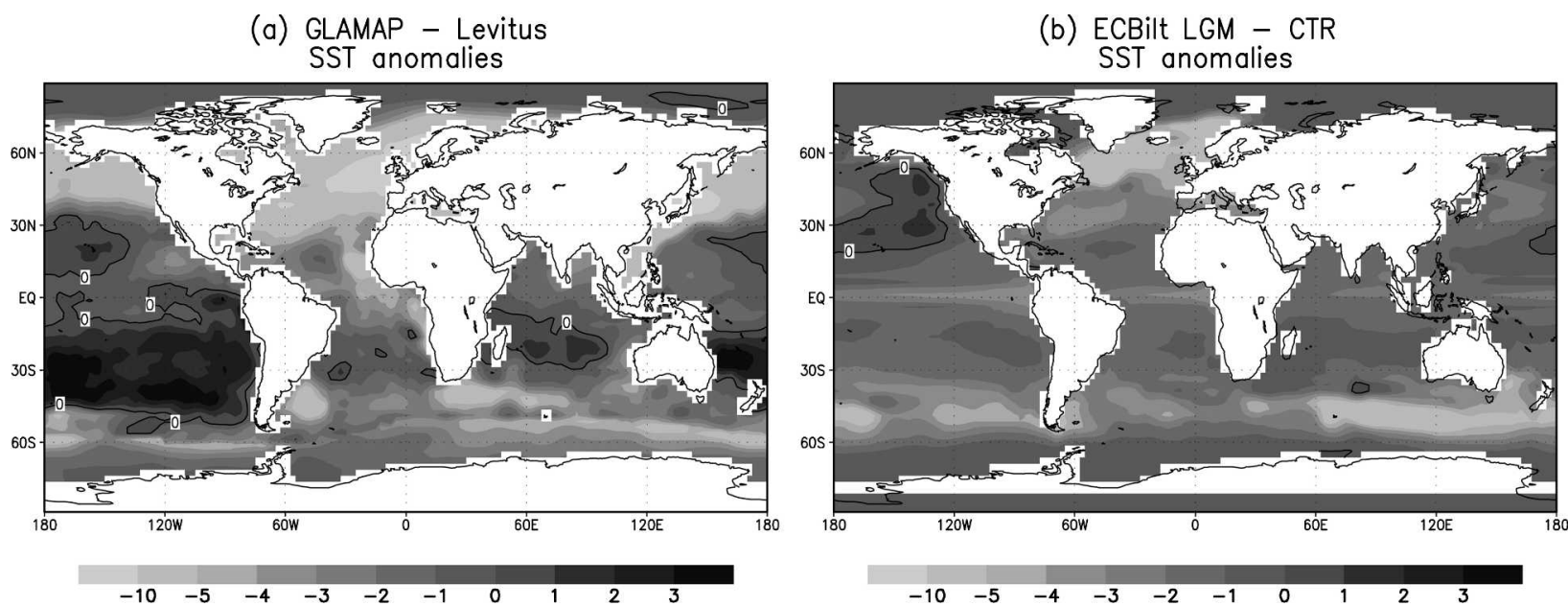

FIG. 7. (a) SST reconstructed difference between the GLAMAP reconstruction and present day (Levitus data) and (b) the simulated SST difference between the LGM and CTR. 


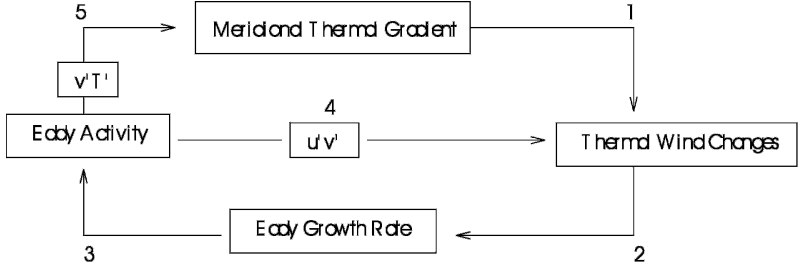

FIG. 8. Schematics of the main feedbacks discussed in this paper.

nance of the topographic forcing during LGM, as shown in Fig. 10b.

\section{b. Feedbacks 2 and 3: Baroclinic eddy activity}

In the following subsections we will focus on the boreal winter season [December-January-February (DJF)], because atmospheric variations in the Northern Hemisphere are strongest during that period. According to the theory of quasi-geostrophic motions, the growth rate of baroclinically unstable perturbations is proportional to the vertical velocity gradient. Based on the results discussed in the previous subsection, we expect that mean circulation changes will lead to a significant modification of the characteristics of baroclinic eddies. This effect can be quantified using the Eady growth rate (Lindzen and Farrell 1980), which is defined as $\sigma_{B 1}=0.31(f / N)|\partial \mathbf{v} / \partial z|$, where $f$ is the Coriolis parameter, $N$ is the Brunt-Väisälä frequency, $z$ is the upward vertical coordinate, and $\mathbf{v}$ is the horizontal wind.

Figure 11 displays the changes of the Eady growth rate during the boreal winter season as simulated by the sensitivity experiments. Particularly strong anomalies of the Eady growth rate during the LGM are found over the jet entrance regions in the Northern Hemisphere, as well as over the ice caps. In accordance with the simulated positive temperature anomaly in the North Pacific and the reduced baroclinicity, we also find a reduced Eady growth rate over the northwestern Pacific in the TOPO and the LGM experiments. Changes of the baroclinicity in the Southern Hemisphere both in the boreal winter and summer season (not shown) are also triggered by large-scale reorganizations of the atmospheric circulation due to topographic forcing changes. The other boundary conditions (orbital, albedo, $\mathrm{CO}_{2}$ forcing) have a relatively small effect on the growth of baroclinic perturbations in the Northern and Southern Hemisphere (not shown). They show a tendency for enhanced baroclinicity in the subarctic, arctic areas. Due to the fact that the Eady growth rate is a nonlinear function of static stability, the different contributions from the sensitivity experiments do not simply add up to the total Eady growth rate during the LGM. Changes in baroclinicity (Fig. 11) lead to changes of the characteristics of baroclinic eddies due to changes of the vertical wind shear and static stability. These changes are documented in Fig. 12 depicting the transient eddy kinetic energy (EKE) [EKE $\left.=(1 / 2) \overline{\left(u^{\prime 2}+v^{\prime 2}\right)}\right]$ for the five simulations, with overbars denoting the time mean and primes the deviation therefrom. The transient eddies are extracted from daily model data and have been temporally filtered using a high-pass filter to include only systems with growth and decay with time scales smaller than 6 days.

As can be seen from Fig. 12a the simulated mean storm tracks are well placed in comparison with more complex CGCMs and the observations (Stendel and Roeckner 1998). The amplitude of the storm tracks, however, is dependent on the atmospheric model resolution, as discussed by Dong and Valdes (2000) and Stendel and Roeckner (1998). Due to the low atmospheric resolution of ECBILT (T21) we obtain an underestimation of the EKE at $500 \mathrm{hPa}$ by a factor of 2 over the Eastern Hemisphere and by a factor of 3 in the North Atlantic area.

Figures $12 \mathrm{~b}-\mathrm{f}$ show the response of the storm tracks during the boreal winter season to the different glacial boundary condition changes. We clearly see an intensification of the Pacific storm track in the $\mathrm{CO}_{2}$ simulation (Fig. 12c). However, in comparison with the topography sensitivity experiment (TOPO), the other boundary conditions induce only marginal changes in storm track intensity. The TOPO simulation exhibits a $30 \%$ weakening of the storm track in the Pacific, whereas an intensification can be observed over the northern North Atlantic (Fig. 12e). The dipole-like response pattern in the North Atlantic area for the TOPO and LGM simulation is a manifestation of a northward shift of storm track, in accordance with the modeling results of Hall et al. (1996).

The diagnosed changes of the storm-track intensity (Fig. 12) are in good agreement with the changes of the Eady growth rate (Fig. 11), thereby, supporting the findings by Hoskins and Valdes (1990) that showed the close relationship between the Eady growth rate and the storm tracks.

\section{c. Feedback 4: Eddy-mean flow interactions}

As shown in many studies (e.g., Jeffreys 1926), the transient eddies may feed back onto the zonal and timemean flow circulation. The momentum cycle in the atmosphere requires a two-sided interaction between eddies and the mean circulation. It can be shown that the zonal mean circulation is decelerated/accelerated by the meridional convergence/divergence of the zonally 

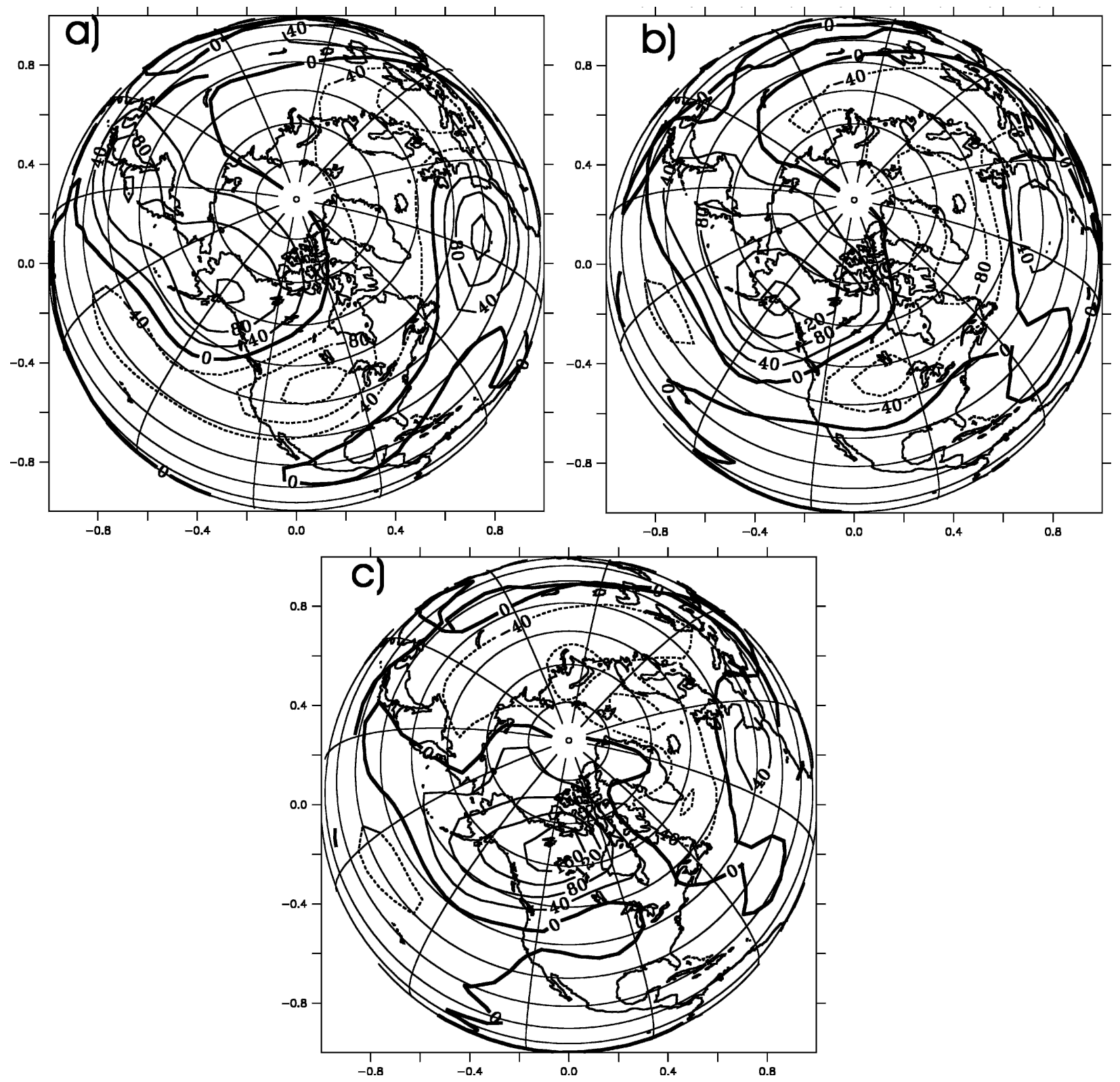

FIG. 9. Difference of the DJF stationary eddy geopotential height field (m) between the LGM and CTR simulation at the (a) 200-, (b) 500-, and (c) 800-hPa levels.

averaged transient eddy momentum fluxes. The meridional and zonal wind components of transient eddies are highly correlated, which leads to a net meridional transport of zonal momentum in the atmosphere. In turn, a modified mean circulation has the potential to modify the eddy characteristics both in a barotropic and baroclinic framework. Here an attempt is made to quantify this interaction for the five sensitivity experiments described above.

Figure 13 depicts the zonally averaged transient eddy momentum flux of the high-pass-filtered transient ed- dies for the CTR run and the anomalies for the TOPO and LGM simulations. As a consequence of the topographic forcing (Fig. 13b) we observe a large negative gradient of the eddy momentum flux near $30^{\circ} \mathrm{N}$. This leads to an intensification of the upper-level westerlies at about $30^{\circ} \mathrm{N}$, thereby opposing the total zonal mean wind reduction shown in Fig. 10. It can be shown that the zonally integrated eddy momentum flux anomaly of the stationary waves is about 4 times larger than that of the transient waves and of opposite sign. The stationary wave flux convergence leads to a weakening of the 
(a) Zonal wind CTR

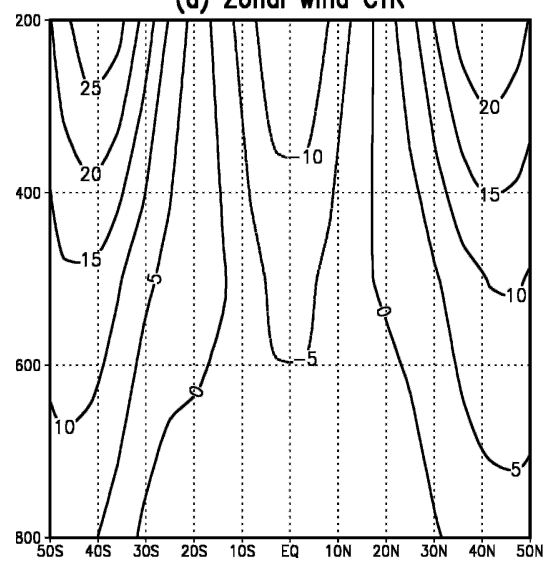

(b) Zonal wind TOPO - CTR

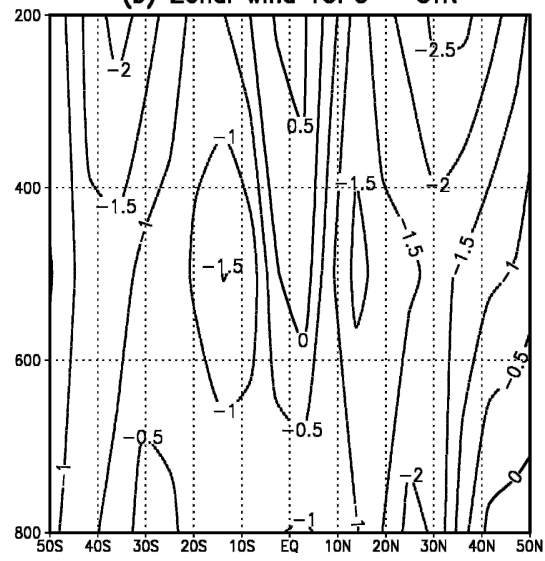

(c) Zonal wind LGM - CTR

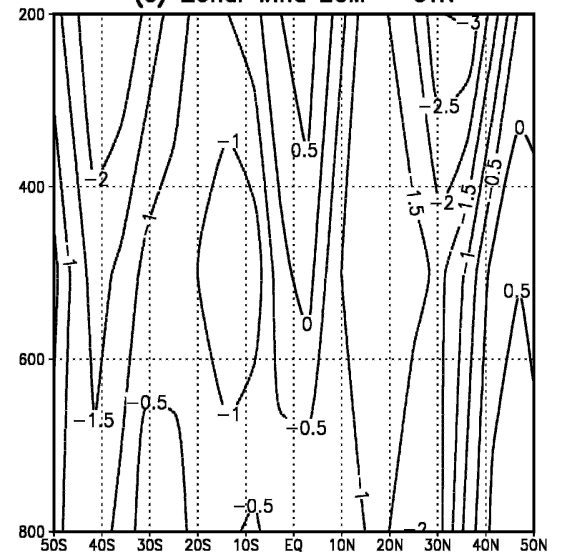

FIG. 10. (a) Time-mean and zonally averaged zonal velocity component $\left(\mathrm{m} \mathrm{s}^{-1}\right)$ for the CTR run. (b) Anomalies of the zonal mean winds simulated by the TOPO with respect to CTR. (c) Same as (b), but for LGM.

zonal mean jet, in accordance with Fig. 10. This illustrates that on a zonal mean basis the topographically induced stationary eddies weaken the jet stream, which in turn, leads to a weakening of the vertical wind shear, thereby reducing transient eddy activity. Changes of the momentum flux convergence of the transient eddies, however, lead to an intensification of the zonal mean flow. Hence, a delicate balance is established between stationary and transient wave activity, via weakening and strengthening of the zonal mean flow, respectively.

To obtain more regional information on the eddymean flow interactions we use further diagnostic methods. Hoskins et al. (1983) proposed a diagnostic framework to analyze the dynamical interaction between transient eddies and the mean flow using the so-called two-dimensional $\mathbf{E}$ vector. Here $\left.\mathbf{E}=\overline{\left(v^{\prime 2}-u^{\prime 2}\right.}, \overline{-u^{\prime} v^{\prime}}\right)$ contains information on the shape and the propagation characteristics of transient eddies. The divergence of $\mathbf{E}$ yields information on the eddy-mean flow interactions. Regions of divergent $\mathbf{E}$ are associated with an intensification of the mean westerly flow, whereas convergent $\mathbf{E}$ can be interpreted as an easterly mean flow forcing. Figure 14 shows $\mathbf{E}$ as computed from the high-pass transient eddies at the 500-hPa level during the boreal winter season. Since the changes in ORB and $\mathrm{CO}_{2}$ experiments are too small they are not shown here.

In the control simulation, the $\mathbf{E}$ vectors are predominantly zonal and have a westerly direction, implying that the transient wave activity propagates faster than the mean flow. Over the North Atlantic, E shows a convergence in the subtropics, resulting in easterly flow acceleration. Furthermore, over the North Pacific E diverges from east Asia to the middle of the storm track. This is consistent with the observed tendency of the eddies to enhance the upper-level westerly flow across the North Pacific (Hoskins et al. 1983).

In the LGM simulation, the $\mathbf{E}$ vector is weaker over the North Pacific, resulting in weaker divergence in the northwest Pacific, thereby leading to an eddy-induced anomalous slowdown of the westerlies at $500 \mathrm{hPa}$. Furthermore, the westward anomalies of the $\mathbf{E}$ vector in the LGM and the TOPO simulation indicates that wave activity propagates slower that in the CTR simulation. In addition, these westward anomalies of $\mathbf{E}$ imply that the synoptic eddies are zonally elongated (see Figs. $14 b, c)$.

Over the North Atlantic region and the Laurentide ice sheet $\mathbf{E}$ changes mostly meridionally. According to the relationship between eddy momentum flux divergence and the time-mean zonal mean flow acceleration, the northward anomalies of $\mathbf{E}$ in the North Atlantic region are associated with a deceleration of the jet stream and an acceleration to the south of it. According to the schematics in Fig. 8, this slowing down of the mean zonal circulation originates from several contributions. The topographic barrier of the Laurentide ice sheet creates an upstream-blocking situation in the North Pacific that slows down the westerlies. Therefore, latent heating anomalies generate a positive SST anomaly in the northeastern Pacific that also leads to changes in the vertical wind shear, slowing down upperlevel westerlies. In turn this leads to a reduced meridional eddy momentum transport and a negative zonal component of the $\mathbf{E}$ vector in the northwestern Pacific, providing another break for the upper-level westerlies.

One disadvantage of the two-dimensional E-vector concept originates from the fact, that it captures both changes of the baroclinic and the barotropic eddymean flow interactions and that its local interpretation 
(a) CTR

DJF Eady growth $500 \mathrm{hPa}\left[\right.$ day $\left.^{\wedge}-1\right]$

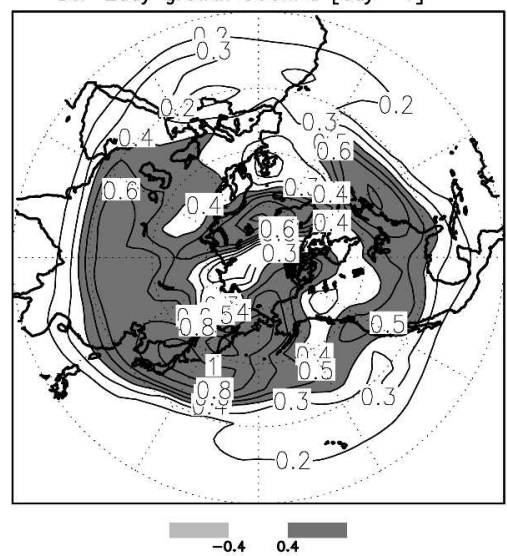

(d) ORB - CTR

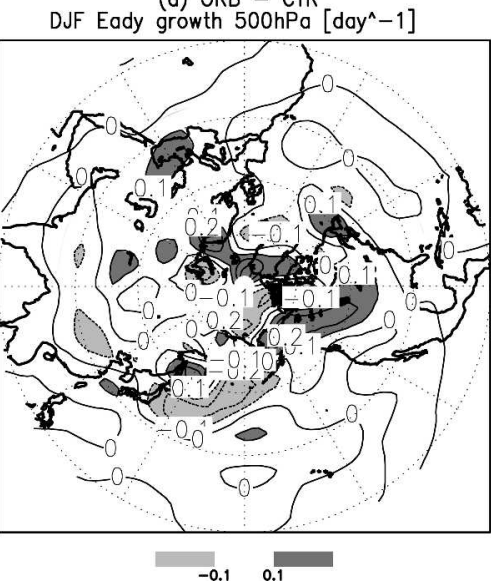

(b) ALBEDO - CTR

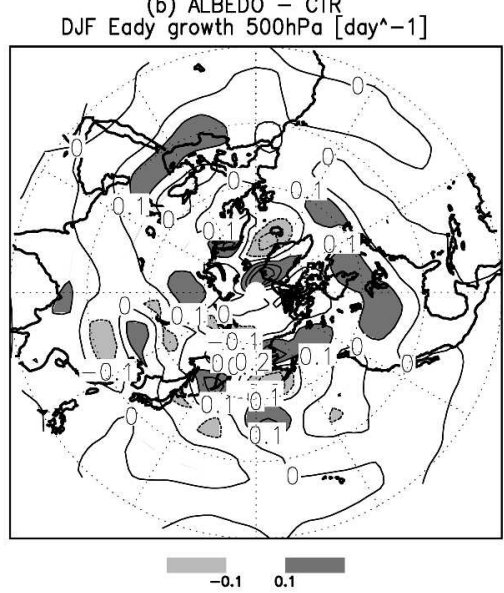

(e) TOPOGRAPHY - CTR

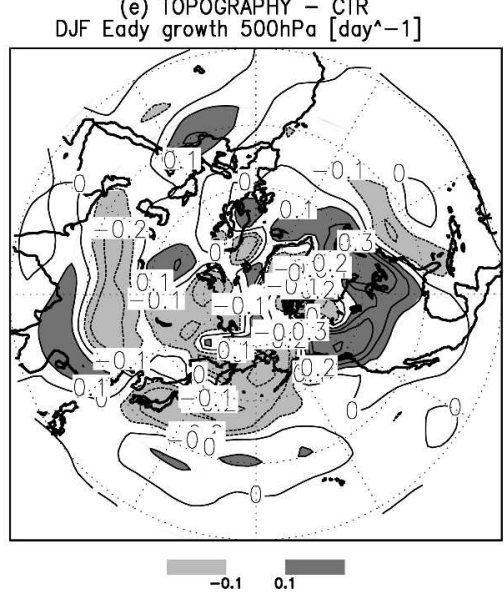

(c) $\mathrm{CO} 2$ - CTR

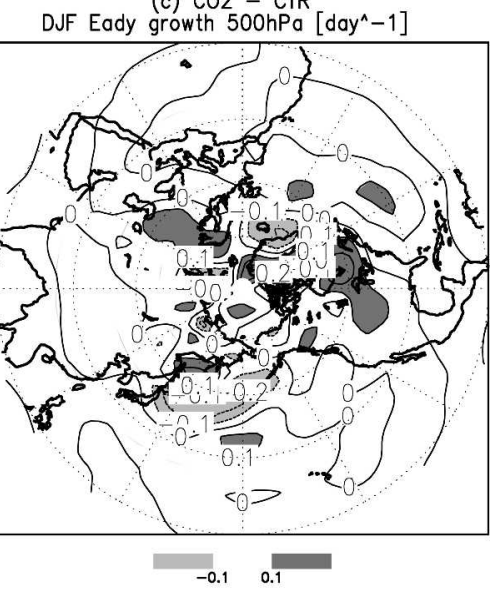

(f) LGM - CTR

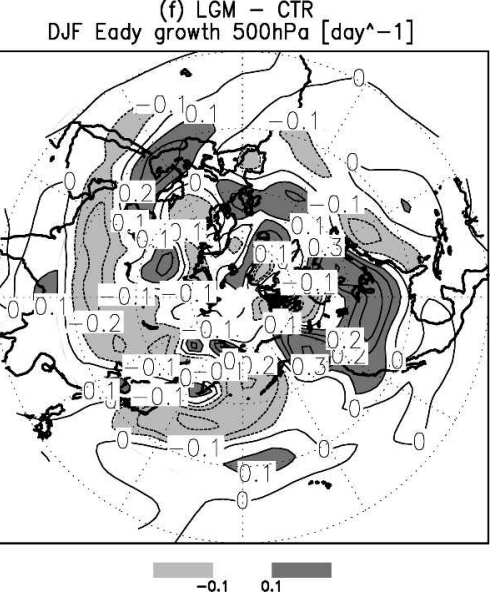

FIG. 11. Mean Eady growth rate in DJF (day ${ }^{-1}$ ) for (a) CTR, (b) ALB-CTR, (c) $\mathrm{CO}_{2}-\mathrm{CTR}$, (d) ORB-CTR, (e) TOPO-CTR, and (f) LGM-CTR.

may be problematic. To disentangle these two contributions more objectively and in detail we diagnose the following contributions in the transient barotropic production (Wallace and Lau 1985) and baroclinic conversion rates. The barotropic conversion rate can be computed from the scalar product of the two-dimensional $\mathbf{E}$ vector and the gradient of the time-averaged zonal velocity $(\mathbf{E} \cdot \nabla \bar{u})$. To obtain the baroclinic energy production $K_{\mathrm{bc}}$ we use the following relation: $K_{\mathrm{bc}}=f\left(u^{\prime} v_{a}^{\prime}-\right.$ $\left.v^{\prime} u_{a}^{\prime}\right)$, where $\left(u_{a}, v_{a}\right)$ represents the two-dimensional ageostrophic velocity and $f$ is the Coriolis parameter. Negative values of these conversion rates indicate a mean flow acceleration and reduced eddy activity.

Figure 15 shows the baroclinic production rate of transient eddy kinetic energy. In the CTR experiment, it is positive in the regions of highest baroclinicity, resulting in a mean flow deceleration, in particular in the North Pacific jet entrance region. The North Atlantic baroclinic production of eddy kinetic energy is weaker than in the Pacific. The presence of glacial albedo (ALB experiment) leads to an intensification of the storm track anomalies in the eastern and centralnorthern Pacific (Fig. 15b). These changes are also captured by the Eady growth rate (Fig. 11). In the TOPO simulation, the baroclinic eddy production is reduced in the western North Pacific, thereby leading to an acceleration of the mean flow. Furthermore, an enhanced baroclinic eddy production rate is simulated over the ice caps, owing to the enhanced baroclinicity in these regions. The baroclinic production rate during the LGM (Fig. 15d) is mostly governed by the topographic effect.

The role of barotropic processes for the eddy kinetic energy budget is depicted in Fig. 16. In the CTR simulation, barotropic instability is positive in the jet entrance regions, leading to a mean flow reduction. Far- 

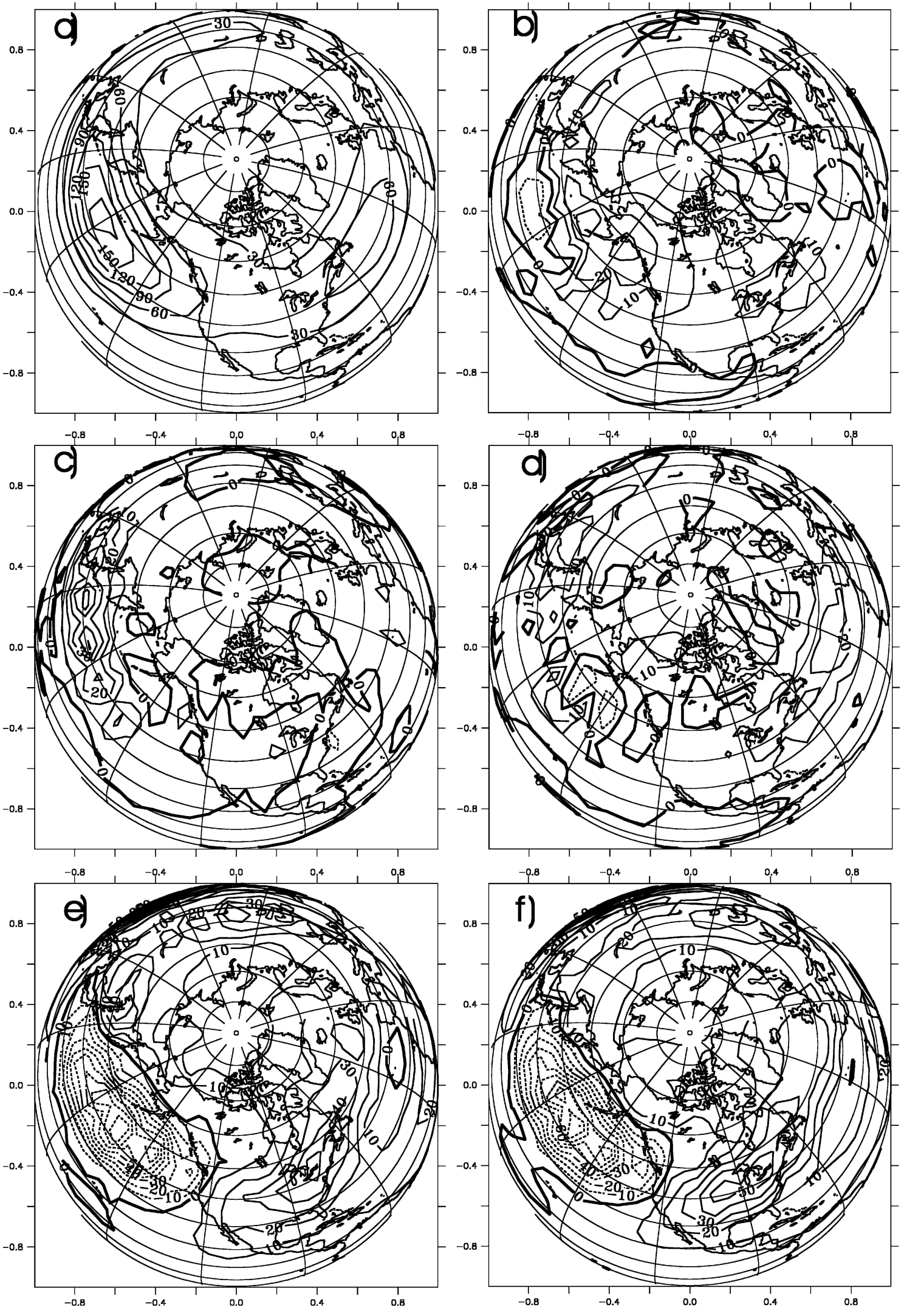

FIG. 12. Same as Fig. 5, but for the time-mean-averaged DJF high-pass EKE $\left(\mathrm{m}^{2} \mathrm{~s}^{-2}\right)$ at $500 \mathrm{hPa}$. 
(a) DJF tran. mom. flux CTR

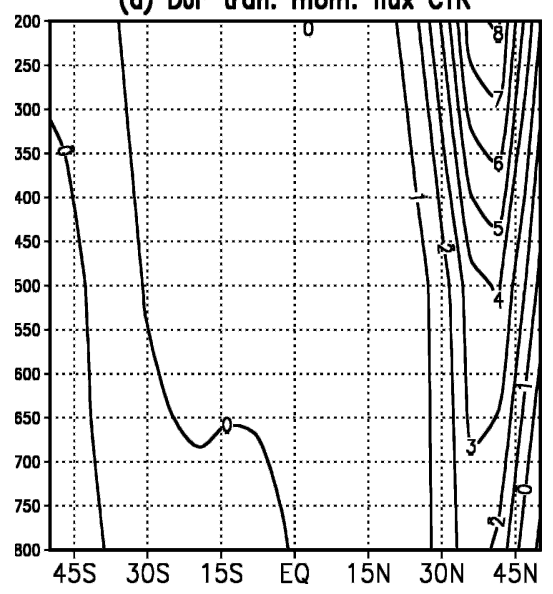

(b) DJF tran. mom. flux TOPO - CTR

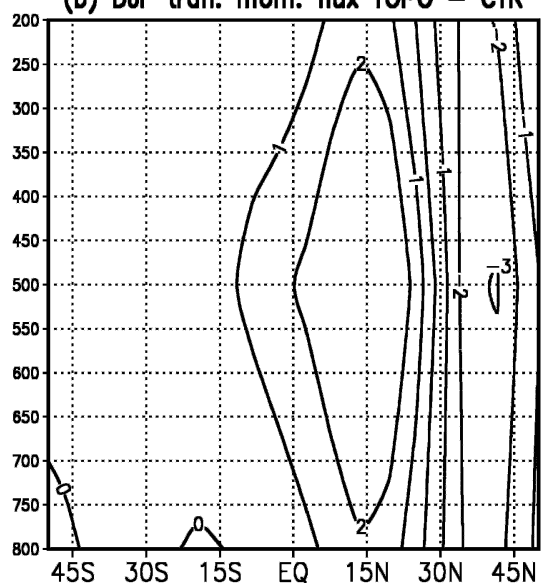

(c) DJF tran. mom. flux LGM - CTR

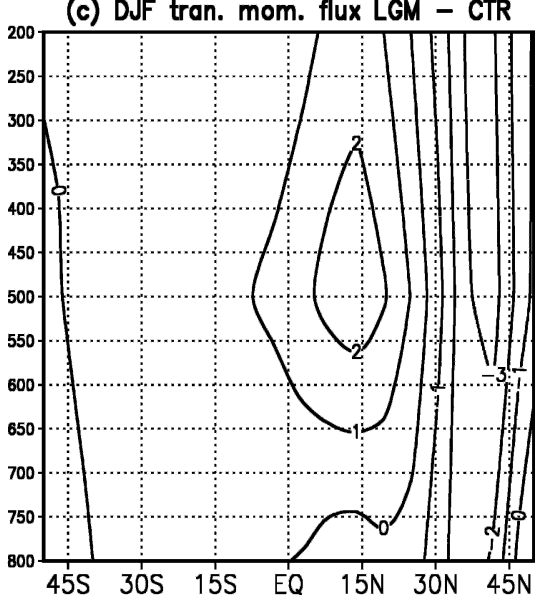

FIG. 13. Same as Fig. 10, but for the zonally averaged transient eddy momentum flux.

ther downstream, barotropic eddies feed the mean flow, in accordance with the fact that the divergence of the $\mathbf{E}$ vector induces westerly flow acceleration (see Fig. 14). Barotropic conversion anomalies between the ALB and CTR experiments show small changes in the Western Hemisphere but slightly larger values in the Asia/Pacific sector (Fig. 16b). Despite the small-scale structure of the TOPO and LGM anomalies, an increase of barotropic energy conversion over the eastern North Pacific and over the Laurentide ice sheet is simulated, thereby decreasing the mean flow in that area. In contrast, a strong mean flow acceleration (negative baroclinic production and barotropic conversion rates) can be observed in the northwestern Pacific. Over the North Atlantic region, the barotropic changes have a small-scale structure, with a slight tendency for an intensification of barotropic energy conversion over the northern North Atlantic.

Baroclinic and barotropic processes modulate the storm track activity over the North Pacific, Laurentide, and North Atlantic area in a coherent way that is consistent with the simulated eddy high-pass kinetic energy, that is, a weakening of the western Pacific storm track, an intensification over the Laurentide ice cap, and a northward displacement over the North Atlantic. Both, baroclinic and barotropic processes add to a mean flow weakening over the North Pacific.

\section{d. Feedback 5: Heat transport due to transient eddies}

The transient eddies do not only transport momentum but also heat poleward. To understand how changes in the characteristics of the baroclinic eddies influence the temperature distribution in the atmosphere, we study the eddy-driven temperature (heat) flux focusing on the high-pass-filtered transient eddies.
Figure 17 shows the low-level $(650 \mathrm{hPa})$ northward eddy temperature flux for the control simulation and the five sensitivity experiments. The simulated $\overline{v^{\prime} T^{\prime}}$ in the CTR simulation (Fig. 17a) compares well qualitatively with the observations and previous modeling results (Dong and Valdes 1998). However, our simulation overestimates the North Pacific temperature flux as compared to the observations, probably as a result of the intense simulated zonal wind component in the North Pacific.

The differences in $\overline{v^{\prime} T^{\prime}}$ between the ALB and CTR simulations are displayed in Fig. 17b. The most significant changes in ALB occur over Eurasia. The $\mathrm{CO}_{2}$ experiment shows a significant enhancement of the heat transport over the North Pacific, as a result of enhanced eddy activity (see Fig. 12), due to lower temperatures in the North Pacific (see Fig. 5). In the ORB experiment the $\overline{v^{\prime} T^{\prime}}$ hardly changes as compared to CTR.

The eddy temperature flux anomalies between TOPO and CTR are plotted in Fig. 17e. The northward temperature flux resulting from the changes in topography shows a reduction of the eddy activity in the storm track entrance regions. In the North Pacific area this weakened heat transport is consistent with the reduced baroclinicity (see Fig. 11). In the North Atlantic storm track region, however, reduced poleward temperature fluxes are simulated, as a result of a northward shift of the Atlantic storm track (see Fig. 12).

Another striking feature of the glacial LGM topography experiment is the strong $\overline{v^{\prime} T^{\prime}}$ over central Asia, which also corresponds to an area of enhanced barotropic instability (Fig. 16d). This feature is likely a result of an enhanced horizontal velocity shear downstream of the Eurasian ice sheet, in response to topographic stationary wave forcing. It does not show up as a major feature in the Eady growth rate, which charac- 

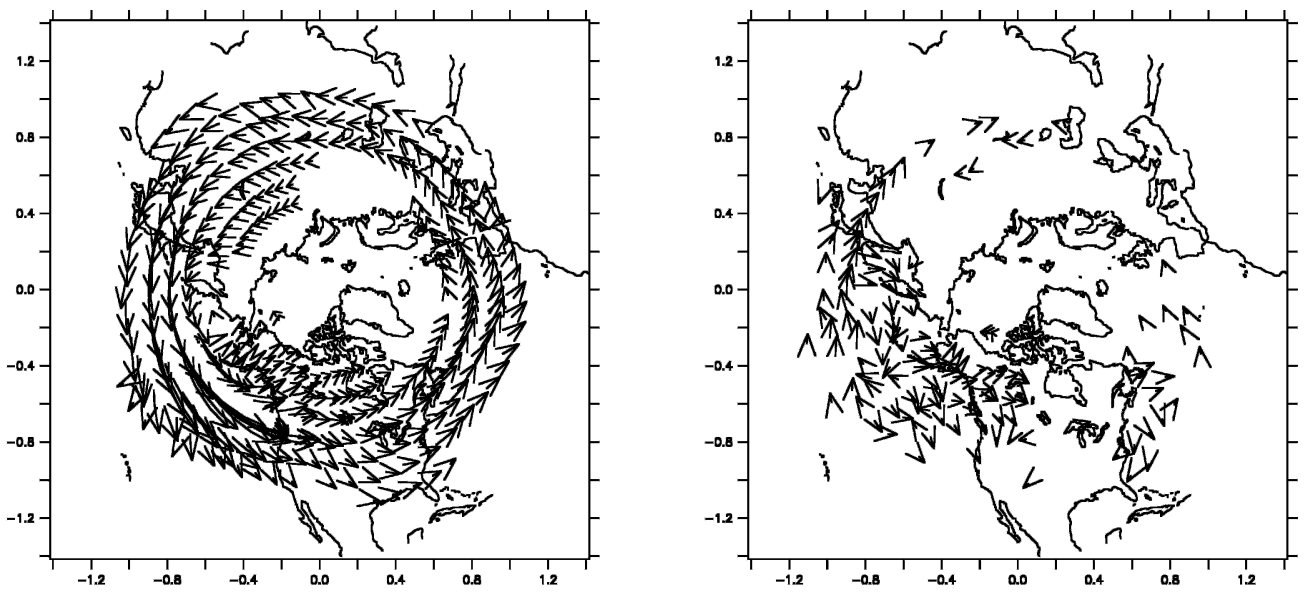

a

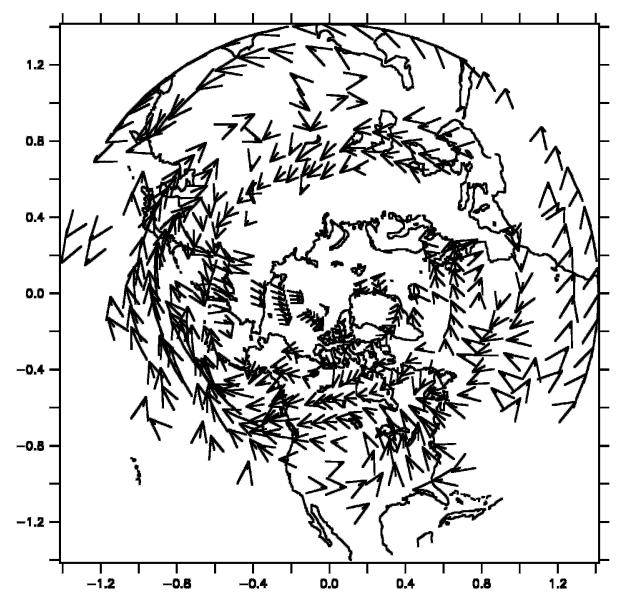

C

FIG. 14. Averaged 500-hPa high-pass E vector in DJF $\left(\mathrm{m}^{2} \mathrm{~s}^{-2}\right.$ ) for (a) CTR, (b) ALB-CTR, (c) TOPO-CTR, b

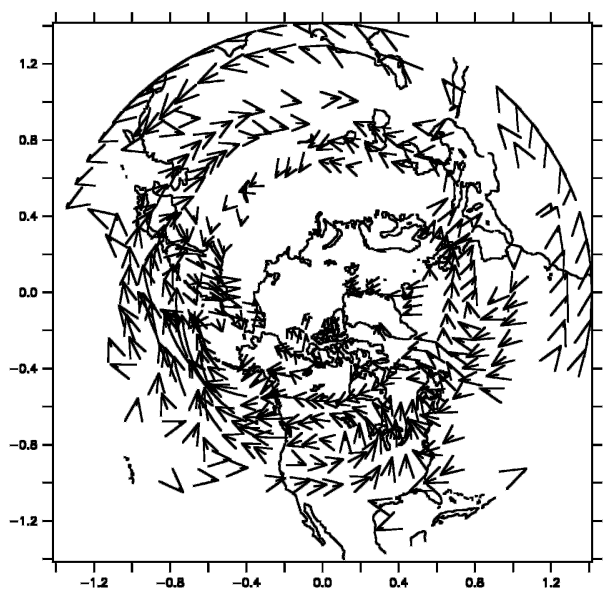

$\rightarrow 10.0$ and (d) LGM-CTR.

terizes the role of vertical shear on transient eddy activity.

The northward shift of the storm-track position in the North Atlantic area has a significant effect on snow accumulation in high latitudes and hence on the ice sheet mass budget mainly over east Greenland and Scandinavia, as discussed by Kapsner et al. (1995).

The LGM simulation reproduces the main features described in the TOPO simulation (Figs. 17e,f), with contributions from the other boundary conditions over the arctic and subarctic areas.

Changes in the heat transport in turn modify the three-dimensional temperature structure in the atmosphere. The weakened North Pacific temperature flux enhances the thermal gradient in the atmosphere, thereby providing a negative feedback for the weak storm-track activity. On the other hand, the weakened heat transport in the subtropical North Atlantic has the tendency to augment the meridional thermal gradient across the North Atlantic drift, thereby leading to an enhanced transient activity in the northern North Atlantic. This effect may help to maintain the northward displacement of the North Atlantic storm track as labeled in Fig. 8 by 5 .

\section{Consequences for precipitation and snowfall}

Previous sections have discussed the role of LGM boundary changes in reorganizing atmospheric flow and its synoptic variability. Changes of the transient eddy activity are expected to also result in extratropical precipitation, and snowfall anomalies.

Figure 18 shows the simulated snowfall anomalies between the ALB, TOPO, and LGM with respect to 

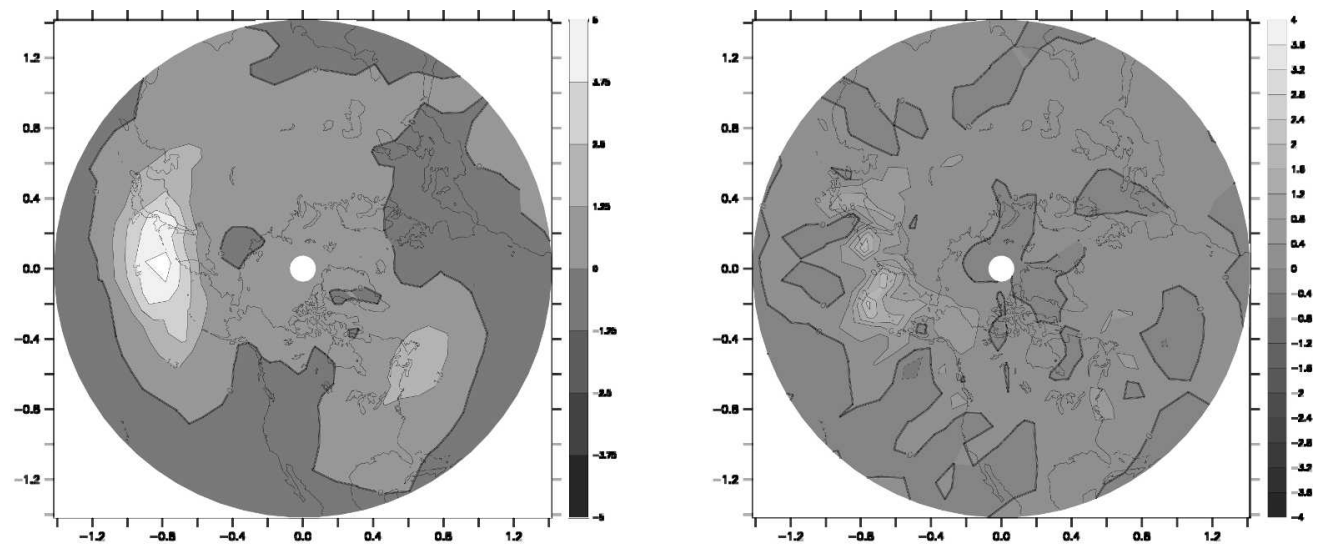

a

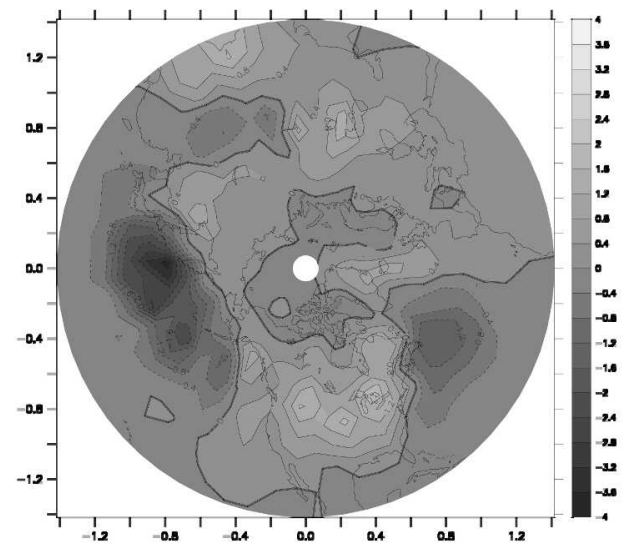

b

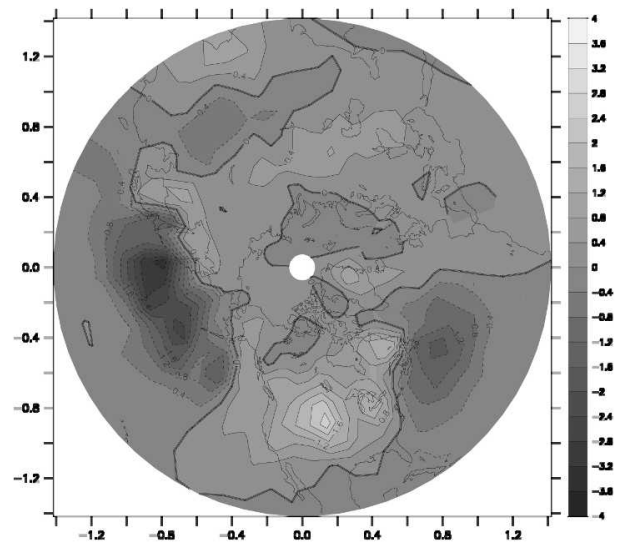

C

d

FIG. 15. High-pass eddy baroclinic production rates at $500 \mathrm{hPa}\left(10^{-4} \mathrm{~m}^{2} \mathrm{~s}^{-3}\right)$ for (a) the CTR, (b) the difference between ALB and CTR, (c) TOPO and CTR, and (d) LGM and CTR.

the CTR experiment. Albedo changes induce positive snowfall anomalies over the Northern Hemispheric continents of the order of $100 \mathrm{~m}(1000 \mathrm{yr})^{-1}$ (Fig. 18a). This leads to an enlargement of the area with enhanced albedo, thereby cooling the Northern Hemisphere even more and leading to enhanced snowfall. This positive feedback is known as the snow-albedo feedback.

The effect of the ice sheet height to the snowfall patterns is displayed in Fig. 18c. Large positive anomalies are simulated over the eastern part of the Laurentide ice sheet, over the North Atlantic, eastern Greenland, and the Scandinavian ice sheets. Furthermore, a dipolelike structure can be see in the Southern Hemisphere.

The LGM anomalies in the Northern Hemisphere attain values of up to $400 \mathrm{~m}(1000 \mathrm{yr})^{-1}$ and are mostly topographically forced. A comparison with Fig. 12 suggests that the intensification and northward shift of the storm track is responsible for the simulated snowfall anomalies over the North Atlantic and European area. These results imply that the topographic changes are an important positive feedback for the buildup and maintenance of the glacial ice sheets (as suggested by Dong and Valdes 1998).

\section{Summary and discussion}

Using a coupled global-atmosphere-sea ice model of intermediate complexity we have analyzed the effect of topographic, albedo, $\mathrm{CO}_{2}$, and orbital forcing during the LGM on the mean atmospheric circulation and its synoptic variability. Among these forcing factors, topographic changes are the most important ones in changing large-scale atmospheric flow. The presence of the Laurentide and Scandinavian ice sheets induces largescale blocking situations to the west of the topographic barrier and stationary troughs to the east of the ice sheets. These stationary wave anomalies generate 


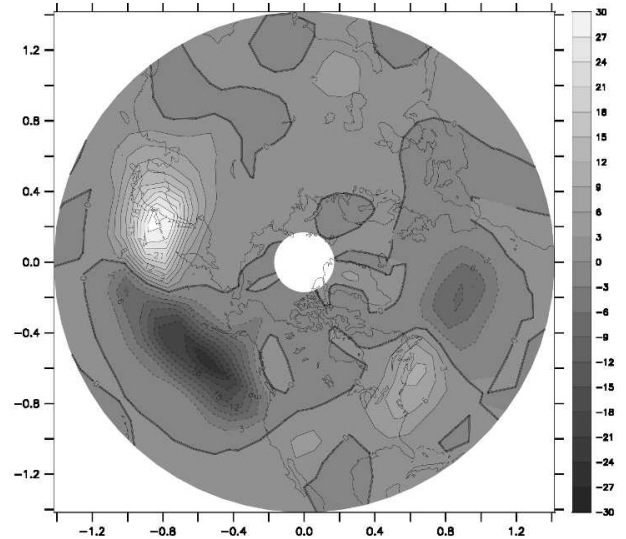

a

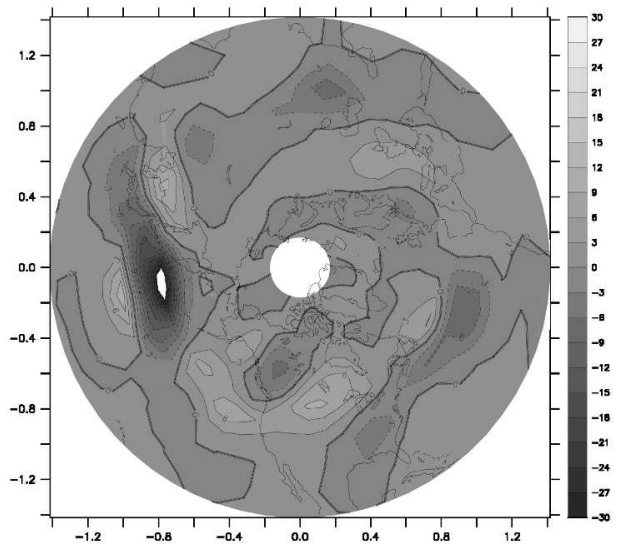

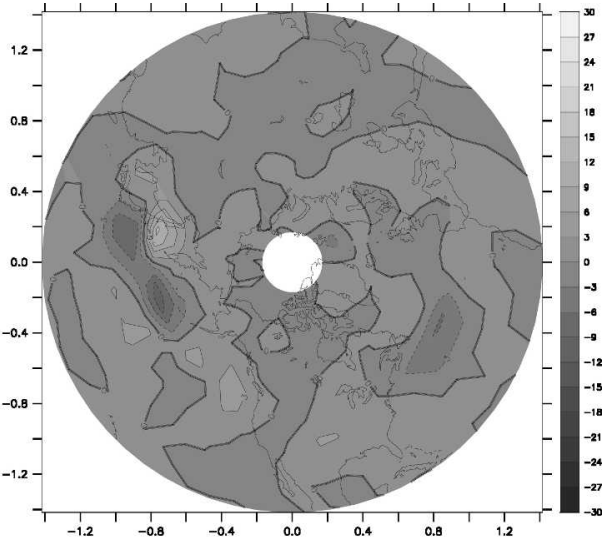

b

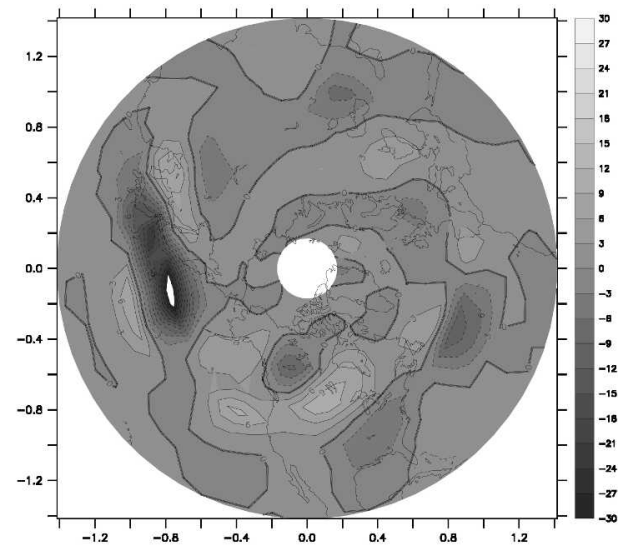

C

d

FIG. 16. Same as Fig. 15, but for high-pass eddy barotropic conversion rates.

changes of the SSTs, in particular in the North Pacific and North Atlantic, due to changes in sensible and latent heat fluxes and ocean dynamic heating (Timmermann et al. 2004). The simulated SST anomaly patterns exhibit some similarities with the CLIMAP (1981) reconstruction in the Pacific area and with the GLAMAP SST and sea ice reconstruction in the North Atlantic (Sarnthein et al. 2003; Pflaumann et al. 2003). However, in our model simulation, the equatorial Pacific SSTs are about $1^{\circ}-1.5^{\circ}$ lower than in the CLIMAP reconstruction. The simulated permanent La Niña state is associated with reduced tropical rainfall, as reconstructed from lake level data in the eastern equatorial Pacific area (Kohfeld and Harrison 2000). On the other hand, it is well known that under present-day conditions a $\mathrm{La}$ Niña event induces warming of the North Pacific area (Lau and Nath 1996), due to changes of the latent and sensible heat fluxes. Hence, in addition to the effect of the upstream-blocking situation on SSTs, there is a tropical teleconnection (which is even simulated in our quasi-geostrophic model) triggered by the La Niña state, which reinforces the extratropical SST effect in the North Pacific. Due to the low climate sensitivity of our coupled model the reduced radiative forcing due to the $\mathrm{CO}_{2}$ lowering cannot compensate for this North Pacific warming. The associated positive precipitation anomaly is also consistent with Californian lake level reconstructions (Kohfeld and Harrison 2000). The atmospheric response to the lower tropical temperatures is an intensification of the equatorial trade winds (as documented in additional sensitivity experiments that are not shown here). In the North Pacific, the positive temperature anomalies have an important effect on the meridional temperature gradient in the atmosphere. In turn, the thermal wind and the vertical wind shear of the Pacific jet stream are weakened.

In the North Atlantic area, the situation is more complex, as the downstream low of the Laurentide ice sheet is interacting with the upstream high of the Scandinavian ice sheet. This leads to a particular mean flow 

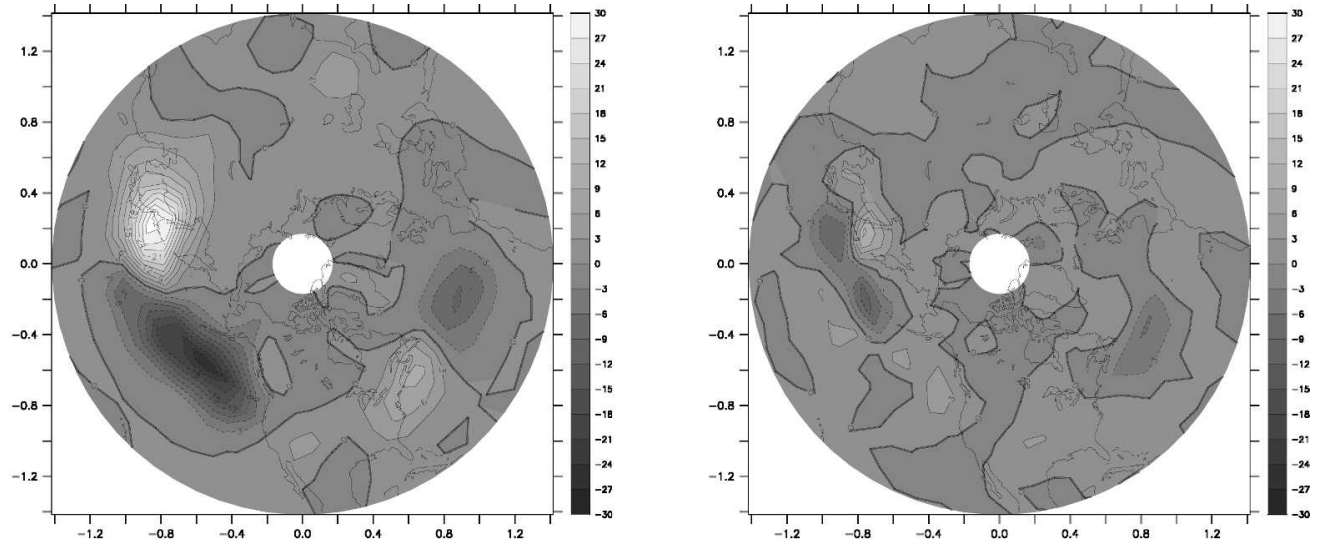

a

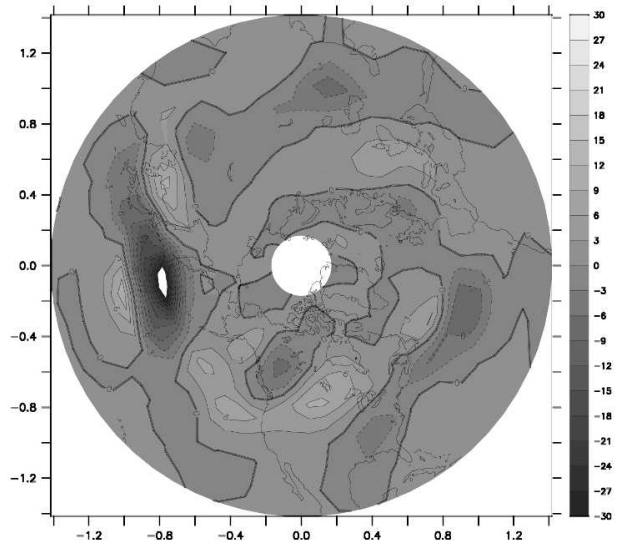

b

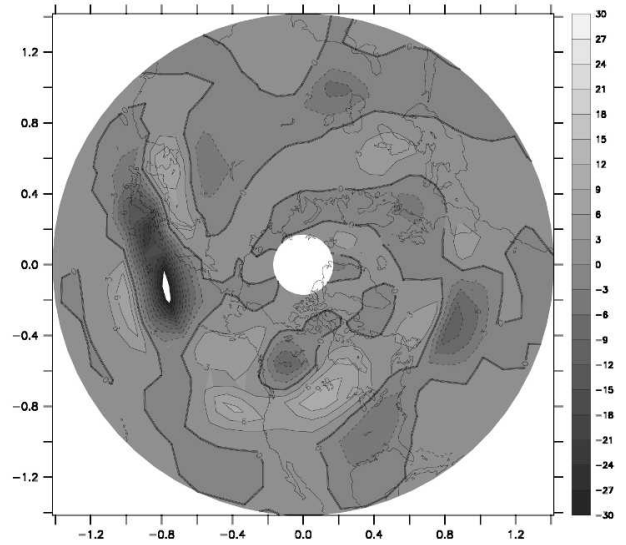

C

d

FIG. 17. Same as Fig. 15, but for the time-mean DJF northward temperature flux in DJF at $650 \mathrm{hPa}\left(\mathrm{km} \mathrm{s}^{-1}\right)$.

situation over the North Atlantic that is also characterized by enhanced horizontal shear.

As documented by using the Eady growth rate concept, these changes trigger a reduction of synoptic transient wave activity in the atmosphere in the Eastern Hemisphere. The reduced heat transport by the synop- tic eddies enhances baroclinicity and operates as a negative feedback for the weak Pacific storm-track activity. Furthermore, the reduction of the zonally averaged meridional momentum flux divergence of the synoptic disturbances leads to an intensification of the zonal mean upper-level westerlies and an associated
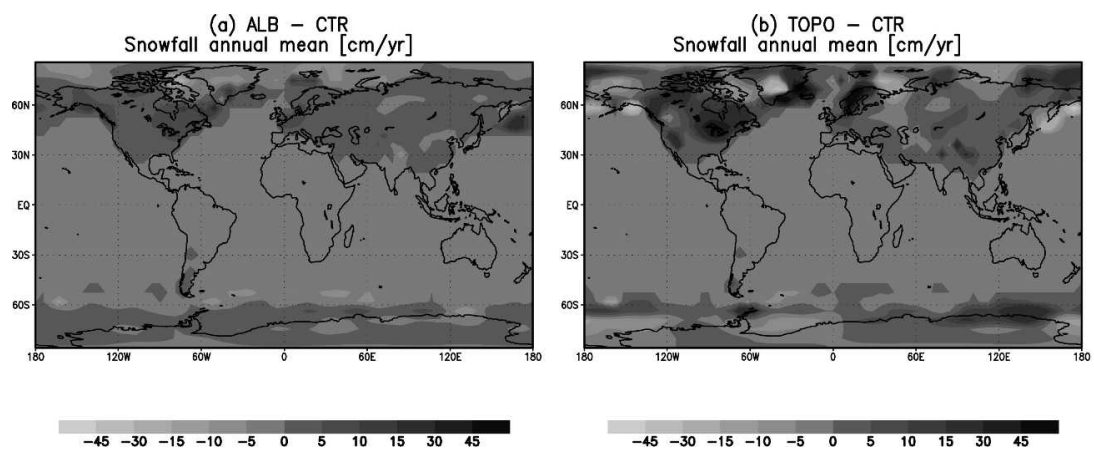

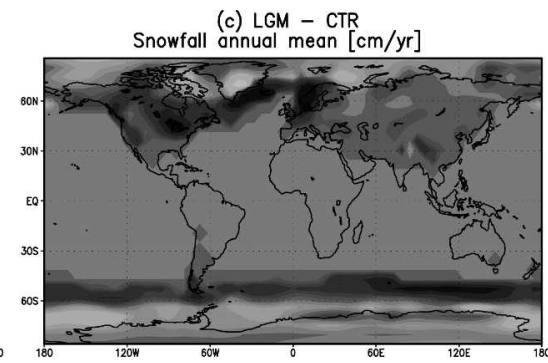

$\begin{array}{lllllllllll}-45 & -30 & -15 & -10 & -5 & 0 & 5 & 10 & 15 & 30 & 45\end{array}$

FIG. 18. Annual mean snowfall anomalies for (a) ALB-CTR, (b) TOPO-CTR, and (c) LGM-CTR ( $\mathrm{cm} \mathrm{yr}^{-1}$ ). 
increase of the storm-track activity due to barotropic and baroclinic instabilities. Hence, the eddy-mean flow interactions act as a negative feedback for the zonally averaged mean flow and its transient eddy activity.

Investigating the local eddy-mean flow interactions using $\mathbf{E}$ vector and barotropic conversion and baroclinic production rates yields a more complex picture: Changes of the baroclinic conversion rates during the LGM are mostly dominated by the topographically induced anomalies. A weakening of the baroclinic EKE production in the northwestern Pacific and an intensification and northward shift of the eddy kinetic energy production region in the North Atlantic is simulated. These changes are consistent with the diagnosed eddy kinetic energy, the eddy heat transport, and the Eady growth rate. However, the divergence anomalies of the two-dimensional $\mathbf{E}$ vector do not match the anomalies of the barotropic and baroclinic conversion rates. Changes of the barotropic eddy energy production are most pronounced in the western North Pacific. A large negative anomaly is associated with reduced barotropic eddy kinetic energy production and an overall acceleration of the westerly mean flow.

Positive barotropic conversion and baroclinic production rates over the Laurentide ice sheets and the far eastern North Pacific have the tendency to decelerate the westerlies, thereby feeding back to the stationary wave changes triggered by orographic forcing (Fig. 9).

Some limitations of our modeling approach originate from the setup of the atmospheric model, which is based on the quasi-geostrophic (QG) approximation and uses just three atmospheric layers. Strictly speaking, the QG assumption holds for low Rossby numbers and for small topographic gradients. Despite this theoretical limitation, we have found (not shown here) that the atmospheric response to tropical SST anomalies is qualitatively well captured. However, the amplitude of the response is diminished in comparison with highresolution primitive equation models, which is mostly due to the low resolution of our model, rather than due to the QG assumption. Furthermore, we have found that the inclusion of topography leads to an improved atmospheric circulation and stationary and transient wave activity as compared to a simulation that neglects orographic forcing. Hence, the model can cope much better both with tropical and orographic forcing than the strict theoretical considerations suggest. Furthermore, the inclusion of the Laurentide ice sheet in a three-layer atmosphere $(200,500$, and $800 \mathrm{hPa})$ may be problematic. However, a comparison with other coupled LGM simulations reveals that our modeling results compare well with those obtained from primi- tive equation multilayer models. As an example, our simulated stationary wave anomalies induced by LGM forcing are qualitatively and quantitatively very similar to those obtained by Kitoh et al. (2001). The same holds for the simulated SST structure. The upstream high and downstream topographic low features of the ice sheets also reproduce well the findings by Rind (1987, see his Fig. 22) and Broccoli and Manabe (1987). Moreover, the results of Shin et al. (2003, see their Fig. 16b), show a near-surface wind response that is similar to ours, both qualitatively and quantitatively.

Our simulated changes of the transient northward temperature flux are comparable with those simulated by the LGM UGAMP simulation of Dong and Valdes (1998), when forced with the CLIMAP (1981) SST anomalies. Our simulated SST anomalies have a structure similar to that of CLIMAP (1981) reconstructions. When the United Kingdom Universities' Global Atmospheric Modelling Programme (UGAMP) model is coupled to a slab ocean, both the simulated SSTs as well as the atmospheric dynamical changes are very different from the CLIMAP (1981) data. This illustrates that a large contribution of the atmospheric circulation changes during the LGM originates from diabatic forcing and probably air-sea interactions. This finding makes an assessment and a model-data comparison particularly difficult. The reason is that different coupled atmosphere-ocean models generate different SST patterns for the LGM. For instance, Bush and Philander (1998) simulate a cooling of the tropical oceans of about $4^{\circ}-6^{\circ}$ in their LGM simulation, whereas the tropical cooling in the Kim et al. (2003) simulation attains values of up to $8^{\circ} \mathrm{C}$. On the other hand, Shin et al. (2003), Hewitt et al. (2001), and Kitoh et al. (2001) find a more moderate cooling of about $2^{\circ}-3^{\circ}$, similar to our results. These large discrepancies are not too surprising, given the uncertainty of future climate projections using state-of-the-art coupled general circulation models. Surprising however is that all of these LGM model simulations are considered to be consistent with reconstructed data. Obviously this suggests that the uncertainty in the reconstructions is so large that it prevents determining which of the model simulations is most realistic. Future research will hope narrow down the uncertainties of paleo data and those of climate model simulations for the LGM considerably. For the time being, we have to cope with the uncertainties still present.

Acknowledgments. This work is supported by CAPES-Brasilia Grant 0794023 and by the Deutsche Forchungsgemeinschaft (DFG) through the Collaborative Research Effort SFB460. 


\section{REFERENCES}

Berger, A., 1978: A simple algorithm to compute long-term variations of daily and monthly insolation. Institut d'Astronomique et de Géophysique, Université Catholique de Lauvain, Louvain-la-Neuve, Belgium, Tech. Rep. 18.

Bjornsson, H., and L. Mysak, 2001: Present-day and last-glacial maximum ocean thermohaline circulation in a zonally averaged coupled ocean-sea-ice-atmosphere model. J. Climate, 14, 1422-1439.

Broccoli, A., and S. Manabe, 1987: The influence of continental ice, atmospheric $\mathrm{CO}_{2}$ and land albedo on the climate of the last glacial maximum. Climate Dyn., 1, 87-99.

Bromwich, D., F. Robask, R. Keen, and J. Bolzan, 1993: Modeled variations of precipitation over the greenland ice sheet. $J$. Climate, 6, 1253-1268.

Bush, A. B. G., and S. G. H. Philander, 1998: The role of oceanatmosphere interactions in tropical cooling during the last glacial maximum. Science, 279, 1341-1344.

Campin, J., and H. Goosse, 1999: A parameterization of dense overflow in large-scale ocean models in z coordinate. Tellus, 51A, 412-430.

CLIMAP, 1981: Seasonal reconstruction of the earth's surface of the last glacial maximum. Geol. Soc. Amer. Map. Chart Ser., MC-36, 1-18.

Cook, K., and I. Held, 1988: Stationary waves of the ice age climate. J. Climate, 1, 807-819.

Crowley, T., 1995: Ice age terrestrial carbon changes revisited. Global Biogeochem. Cycles, 9, 377-389.

DeBlonde, G., and W. Peltier, 1990: A model of late pleistocene ice sheet growth with realistic geography and simplified cryodynamics and geodynamics. Climate Dyn., 5, 103-110.

Dong, B., and P. Valdes, 1998: Simulation of the last glacial maximum climates using a general circulation model: Prescribed versus computed sea surface temperature. Climate Dyn., 14, $571-591$.

— and - 2000: Climates at the last glacial maximum: Influence of model horizontal resolution. J. Climate, 13, 15541573.

Ganopolski, A., S. Rahmstorf, V. Petoukhov, and M. Claussen, 1998: Simulation of modern and glacial climates with a coupled global model of intermediate complexity. Nature, 391, 351-356.

Gent, P., and J. McWilliams, 1990: Isopycnal mixing in ocean general circulation models. J. Phys. Oceanogr., 20, 150-155.

Goosse, H., and T. Fichefet, 1999: Importance of ice-ocean interactions for the global ocean circulation: A model study. $J$. Geophys. Res., 104 (C10), 23 337-23 355.

— E. E. Deleersnijder, T. Fichefet, and M. England, 1999: Sensitivity of a global coupled ocean-sea ice model to the parameterization of vertical mixing. J. Geophys. Res., 104 (C6), 13 681-13 695.

— , F. Selten, R. Haarsma, and J. Opsteegh, 2002: Large sea-ice volume anomalies simulated in a coupled climate model. Climate Dyn., 10, doi:10.1007/s00382-002-0290-4.

Hall, N., B. J. Hoskins, P. Valdes, and C. Senior, 1994: Storm tracks in a high-resolution GCM with doubled carbon dioxide. Quart. J. Meteor. Soc., 120, 1209-1230.

— - B. Dong, and P. Valdes, 1996: Atmospheric equilibrium, instability and energy transport at the last glacial maximum. Climate Dyn., 12, 497-511.

Held, I., and M. Suarez, 1978: A two-level primitive equation atmosphere model designed for climate sensitivity experiments. J. Atmos. Sci., 35, 206-229.

Hewitt, C. D., A. Broccoli, J. Mitchell, and R. J. Stouffer, 2001: A coupled model of the last glacial maximum: Was part of the North Atlantic relatively warm? Geophys. Res. Lett., 28, 1571-1574.

Hoskins, B. J., and P. J. Valdes, 1990: On the existence of storm tracks. J. Atmos. Sci., 47, 1854-1864.

_- I. James, and G. White, 1983: The shape, propagation and mean flow interaction of large scale weather systems. $J$. Atmos. Sci., 40, 1595-1612.

Jeffreys, H., 1926: On the dynamics of geostrophic winds. Quart. J. Roy. Meteor. Soc., 52, 85-104.

Kalnay, E., and Coauthors, 1996: The NCEP/NCAR 40-Year Reanalysis Project. Bull. Amer. Meteor. Soc., 77, 437-471.

Kapsner, W., R. Alley, C. Schuman, S. Anandakrishnan, and P. Grootes, 1995: Dominant influence of atmospheric circulation on snow accumulation in Greenland over the past 18000 years. Nature, 373, 52-54.

Kim, S., G. Flato, and G. Boer, 2003: A coupled climate model simulation of the last glacial maximum. Part 2: Approach to equilibrium. Climate Dyn., 20, 635-661.

Kitoh, A., S. Muakami, and H. Koide, 2001: A simulation of the Last Glacial Maximum with a coupled atmosphere-ocean GCM. Geophys. Res. Lett., 28, 2221-2224.

Kohfeld, K., and S. Harrison, 2000: How well can we simulate past climates? Evaluating the models using palaeoenvironmental datasets. Quat. Sci. Rev., 19, 321-346.

Kuo, H., 1956: Forced and free meridional circulations in the atmosphere. J. Meteor., 13, 561-568.

Lau, N., and M. Nath, 1996: The role of the "atmospheric bridge" in linking tropical pacific ENSO events to extratropical SST anomalies. J. Climate, 9, 2036-2057.

Lindzen, R., and B. Farrell, 1980: A simple approximate result for maximum growth rate of baroclinic instabilities. J. Atmos. Sci., 37, 1648-1654.

Liu, Z., S. Shin, B. Otto-Bliesner, J. Kutzbach, and E. Brady, 2002: Tropical cooling at the last glacial maximum and extratropical ocean ventilation. Geophys. Res. Lett., 29, 1409, doi:10.1029/2001GL013938.

MacAyeal, D., 1993: Binge/purge oscillations of the laurentide ice sheet as a cause of the North Atlantic's heinrich events. $\mathrm{Pa}$ leoceanography, 8, 775-784.

Marshall, J., and F. Molteni, 1993: Toward a dynamic understanding of planetary-scale flow regimes. J. Atmos. Sci., 50, 1792 1818.

Marshall, S., and G. Clarke, 1999: Modeling North American freshwater runoff through the last glacial cycle. Quat. Res., 52, 300-315.

Mellor, G., and T. Yamada, 1982: Development of a turbulence closure model for geophysical fluid problems. Rev. Geophys. Space Phys., 20, 851-875.

Opsteegh, J., R. Haarsma, F. Selten, and A. Kattenberg, 1998: ECBILT: A dynamic alternative to mixed boundary conditions in ocean models. Tellus, 50A, 348-367.

Peltier, W., 1994: Ice age paleotopography. Science, 265, 195-201.

— and L. Solheim, 2004: The climate of the earth at last glacial maximum: Statistical equilibrium state a mode of internal variability. Quat. Sci. Rev., 89, 335-357.

Pflaumann, U., and Coauthors, 2003: Glacial North Atlantic: Seasurface conditions reconstructed by GLAMAP 2000. Paleoceanography, 18, 1065, doi:10.1029/2002PA000774. 
Rind, D., 1987: Components of the ice age circulation. J. Geophys. Res., 92, 4241-4281.

Sarnthein, M., U. Pflaumann, and M. Weinelt, 2003: Past extent of sea ice in the northern North Atlantic inferred from foraminiferal paleotemperature estimates. Paleoceanography, 18, 1047, doi:10.1029/2002PA000771.

Schmittner, A., M. Yoshimori, and A. Weaver, 2002: Instability of the glacial climate in a model of the ocean-atmospherecryosphere system. Science, 295, 1489-1493.

Shin, S. I., Z. Liu, B. L. O. Bliesner, E. C. Brady, J. E. Kutzbach, and S. P. Harrison, 2003: A simulation of the Last Glacial Maximum climate using the NCAR CSM. Climate Dyn., 20,127151.

Shinn, R., and E. Barron, 1989: Climate sensitivity to continental ice-sheet size and configuration. J. Climate, 2, 1517-1537.
Stendel, M., and E. Roeckner, 1998: Impacts of horizontal model resolution on simulated climate statistics in ECHAM. Max Planck Institute of Meteorology, Rep. 253, 57 pp.

Stocker, T. F., 1998: The seesaw effect. Science, 286, 61-62.

Timmermann, A., F. Justino, F.-F. Jin, and H. Goosse, 2004: Surface temperature control in the North and tropical Pacific during the last glacial maximum. Climate Dyn., 23, 353-370.

Wallace, J., and N.-C. Lau, 1985: On the role of barotropic energy conversion in the general circulation. Advances in Geophysics, Vol. A28, Academic Press, 33-74.

Xie, T., and C. Arkin, 1997: Global precipitation: A 17-year monthly analysis based on gauge observations, satellite estimates, and numerical model outputs. Bull. Amer. Meteor. Soc., 78, 2539-2558. 